\title{
Rule-based modeling using wildcards
}

Steven S. Andrews

Fred Hutchinson Cancer Research Center, Seattle, WA, USA

Isaac Newton Institute for Mathematical Sciences, Cambridge, UK

Submitted to Methods in Molecular Biology, Sept. 19, 2016. Accepted Dec. 21, 2016. 


\section{Summary}

Many biological molecules exist in multiple variants, such as proteins with different posttranslational modifications, DNAs with different sequences, and phospholipids with different chain lengths. Representing these variants as distinct species, as most biochemical simulators do, leads to the problem that the number of species, and chemical reactions that interconvert them, typically increase combinatorially with the number of ways that the molecules can vary. This can be alleviated by "rule-based modeling methods," in which software generates the chemical reaction network from relatively simple "rules." This article presents a new approach to rule-based modeling. It is based on wildcards that match to species names, much as wildcards can match to file names in computer operating systems. It is much simpler to use than the formal rule-based modeling approaches developed previously but can also lead to unintended consequences if not used carefully. This article demonstrates rule-based modeling with wildcards through examples for: signaling systems, protein complexation, polymerization, nucleic acid sequence copying and mutation, the "SMILES" chemical notation, and others. The method is implemented in Smoldyn, a spatial and stochastic biochemical simulator, for both the generate-first and on-the-fly expansion, meaning whether the reaction network is generated before or during the simulation.

Key words: rule-based modeling, particle-based simulation, wildcards, reaction networks, spatial simulation, stochastic simulation, Brownian dynamics. 


\section{Introduction}

Since about the time that Boyle posited that matter was composed of minute particles "associated into minute masses or clusters" (1), now recognized as molecules, the dominant paradigm in chemistry has been to classify molecules into chemical species. This paradigm forms the foundation of chemical kinetics $(2,3)$ and is supported by the finding that different molecules of the same species are completely indistinguishable from each other $(4,5)$. Correspondingly, most modern biochemical simulation software represents molecules as members of species, treating all members of a single species identically (see reviews $(6,7)$ ). However, many biological molecules do not fit neatly into these classes. For example, a cell might have a hundred or more DNA molecules, each with a different sequence. Similarly, a cell might have thousands of copies of some protein, but the copies vary according to whether they are bound to other proteins, bound to cofactors, or post-translationally modified with phosphate, methyl, or other moieties.

Several approaches have been developed to represent this molecular variation in computational models. One is to represent every multimer as an explicit graph, including its component monomers and their interconnections (e.g. (8-12)). Here, every molecule is its own entity and the concept of a species as a class of molecules is unnecessary. A second approach is to maintain the species concept, but to include states in the molecule definitions. For example, some biochemical simulators allow molecules to have modification states (13-15), surface-binding states (16), or an entire hierarchy of states (17). A third approach is to define each molecular variant as a separate species, with minimal variation within species. The possible variations can lead to a combinatorial expansion in the number of species (18), leading to the development of so-called rule- 
based modeling methods for automating reaction network expansion from "rules" that describe molecular complexation and modifications (e.g. (19-21)).

I recently followed this last approach, adding rule-based modeling to the Smoldyn simulator (22). Smoldyn is a widely used biochemical simulator that represents molecules as individual particles in 1D, 2D, or 3D space; these molecules diffuse, react with each other, and interact with surfaces $(\mathbf{1 6}, 23,24)$. Smoldyn now supports two types of rule-based modeling. First, it sends any rules in the user's input file that are written in the BioNetGen language (BNGL) to the BioNetGen software $(19,25)$. BioNetGen expands the rules to lists of species and reactions; then, Smoldyn reads the species and reactions, computes diffusion coefficients, graphical display parameters, and surface interactions for the new species, and runs the simulation (22). Second, Smoldyn performs a separate type of rule-based modeling using wildcard characters (22), which is the focus of this article. In this method, a modeler can specify groups of species using wildcard characters, much as a computer user can specify groups of files using wildcard characters. When used in chemical reactions, these wildcards can be used to define new species and new reactions.

Whereas rule-based modeling with formal languages, such as BNGL, were designed around an underlying model of how protein complexation and modification generally works, this is not the case for wildcards. Instead, the wildcard approach is simply a well-defined set of text-replacement tools with which the modeler can create his or her own notational scheme. This offers substantial versatility and generally simplifies input files. However, it can also lead to undesired results if not used carefully. Thus, the 
main text of this article focuses on the precise behavior of the wildcards, while the notes section presents examples that illustrate how the method can be used effectively.

\section{Materials}

Download Smoldyn from http://www.smoldyn.org. Smoldyn is free, open source, and licensed under the relatively permissive LGPL. The download package comes with install scripts, a detailed user's manual, about 100 example input files, related software tools (including BioNetGen), and, if desired, the source code. Install on Macs and Windows with the install scripts, which is generally easy. Install on Linux computers by compiling the source code with CMake and Make, which is also straightforward.

Smoldyn runs on most laptops and larger computers that are less than 5 years old, as well as many older computers. Support is available by e-mailing support@smoldyn.org.

\section{Methods}

\subsection{Running Smoldyn}

To simulate a model in Smoldyn, start by describing the model in the Smoldyn language using a plain text file. Ref. (26) and the Smoldyn User's Manual (included in the download package) describe how to write input files and give suggestions for parameter values.

Run Smoldyn at a shell prompt (a "Terminal" or "Command Line" application) by typing smoldyn myfile.txt, where myfile.txt is your configuration file name. Upon starting, Smoldyn reads model parameters from your configuration file, calculates and displays simulation parameters, and runs the simulation. As the simulation runs, 
Smoldyn displays the simulated system to a graphics window and saves quantitative data to one or more output files.

\subsection{Wildcards for matching}

Molecules in Smoldyn are classified into chemical species and can also adopt any of 5 physical states. These states are in solution (e.g. a cell's cytoplasm) or the 4 surfacebound states called "front," "back," "up," and "down." Originally, the former two surface-bound states were for peripheral membrane proteins and the latter two were for integral membrane proteins, although they are all essentially equivalent in practice. All molecules of a single species and state behave identically, meaning that they have the same diffusion coefficients, graphical display parameters, surface interaction rates, and chemical reaction rates. Any other molecular variation needs to be expressed using separate species. For example, if a model includes the yeast Fus3 protein, which can bind to zero, one, or two phosphate groups (27), then each of its phosphorylation states would need to be represented as a separate species. Alternatively, if a model includes a receptor that diffuses at one rate in normal membrane regions and more slowly in lipid rafts, then this variation would again need to be represented using separate species.

Modeling such variations can lead to a rapid proliferation of separate species and so can become tedious to address. Use of wildcards alleviates this problem because it enables one to represent multiple species at once. For example, if the three Fus 3 species were named Fus3, Fus3p, and Fus3pp, then the species pattern Fus3* would represent all three species. Also, if the receptors mentioned above were named R_normal and R_raft, then the species pattern $\mathrm{R}_{-}{ }^{*}$ would represent both species. More generally, a species 
pattern is a species name that may include wildcard characters. In both of these examples, the '*' wildcard is used to represent variable portions of the species names.

Smoldyn supports text-matching and structural wildcards, where the former ones match to specific portions of the species names and the latter ones enable logical operations in species patterns. The text-matching wildcards include '*', which matches to any zero or more characters, '?', which matches to any one character, and [...], which matches to any one character from a specified list. The structural wildcard characters include 'I', which is an OR operator, '\&', which is a permutation operator, and $\{\ldots\}$, which specifies the order of operation for the other two structural wildcards (the normal order of operations is that ' $\&$ ' takes precedence over 'I'). The structural wildcards are most easily explained through examples, this time using the generic protein monomer names $\mathrm{A}, \mathrm{B}$, and $\mathrm{C}$ : the pattern $\mathrm{AlB}$ matches to either $\mathrm{A}$ or $\mathrm{B}$, the pattern $\mathrm{A} \& \mathrm{~B}$ matches to either $\mathrm{AB}$ or $\mathrm{BA}$, the pattern $\mathrm{A} \& \mathrm{~B} \mid \mathrm{C}$ matches to $\mathrm{AB}, \mathrm{BA}$, or $\mathrm{C}$, and the pattern $\mathrm{A} \&\{\mathrm{~B} \mid \mathrm{C}\}$ matches to AB, BA, AC, or CA. See Table 1.

Internally, when Smoldyn parses the user's input file and expects a species name, it inputs the given text as a species pattern. The pattern may be as simple as a single species name but could also include one or more wildcard characters. If the pattern does not include structural wildcards, then it is an elementary pattern. On the other hand, if it does include structural wildcards, such as the pattern A\&*, then Smoldyn first expands it to a list of elementary patterns; here, Smoldyn would expand the example to A* and *A. Next, Smoldyn scans through its list of species names to see which ones can match the elementary pattern(s). These matching species form a species group. If the pattern arose in a statement that defines species attributes (e.g. difc, for specifying the diffusion 
coefficient), then Smoldyn assigns the same attribute value to all species within the species group. Alternatively, if the pattern arose in a command that outputs information about molecules (e.g. molcountspecies, which counts the number of molecules of a given species or species group), then Smoldyn combines the appropriate information for all of the molecules that are in the species group.

\subsection{Wildcards for substitutions}

Smoldyn also supports wildcards in chemical reaction definitions, where they can be used to specify multiple chemical reactions at once. Smoldyn inputs each chemical reaction equations as a reaction pattern, which again may include wildcards but does not have to.

First, consider elementary reaction patterns, meaning reaction patterns that do not contain structural wildcards. In this case, Smoldyn substitutes any text that the wildcards match for the reactants into the corresponding wildcards in the products. For example, the reaction Ste5 + Fus3* $\rightarrow$ Ste5-Fus3* specifies that any of the three Fus3 species described above can associate with the Ste5 protein (27). In this case, the respective products would be Ste5-Fus3, Ste5-Fus3p, and Ste5-Fus3pp. If the same text-matching wildcard is used multiple times on each side of the equation, then Smoldyn corresponds the first instance in the reactants to the first instance in the products, the second to the second, and so on. For example, if Ste 5 can also be phosphorylated, then Ste $5^{*}+$ Fus $3 *$ $\rightarrow$ Ste $5^{*}$-Fus $3 *$ specifies that the binding reaction occurs for all phosphorylation states of both proteins, and that they maintain their phosphorylation states in the reaction. The correspondence can also be given explicitly using the ' $\$ n$ ' wildcard on the product side of 
a reaction, using any value of $n$ from 1 to 9 , where it represents the $n$ 'th item of matching text. For example, the previous reaction could also be written as Ste $5^{*}+$ Fus $3^{*} \rightarrow$

Ste $51-F u s 3 \$ 2$. Text-matching wildcards in the reactants do not have to appear in the products; for example, Fus $3^{*} \rightarrow \mathrm{X}$ shows that all three Fus3 species decay to the same product. On the other hand, text-matching wildcards in the products must appear in the reactants, meaning that Smoldyn would not accept the reaction $\mathrm{X} \rightarrow$ Fus3*.

Much like the case for species patterns, Smoldyn expands reaction patterns that include structural wildcards to lists of elementary reaction patterns and then performs matching and substitution on these elementary patterns. In the reaction pattern $A \& * \rightarrow$ $\mathrm{X}^{*}$, for example, Smoldyn would first expand it to $\mathrm{A}^{*} \rightarrow \mathrm{X}^{*}$ and ${ }^{*} \mathrm{~A} \rightarrow \mathrm{X}^{*}$, and would then perform matching and substitution on these two elementary reaction patterns. There are a few possible types of expansions. (i) If the reactant and product sides expand to the same number of elementary patterns, then Smoldyn assumes that they correspond to each other sequentially. For example, Smoldyn expands the reaction pattern AIB $\rightarrow$ CID to the two reactions $\mathrm{A} \rightarrow \mathrm{C}$ and $\mathrm{B} \rightarrow \mathrm{D}$. (ii) Smoldyn also accepts patterns that expand to only one elementary pattern on either the reactant or product side, in each case creating a list of reactions that have either the same reactant or product. For example, AlB $\rightarrow X$ expands to $\mathrm{A} \rightarrow \mathrm{X}$ and $\mathrm{B} \rightarrow \mathrm{X}$, and $\mathrm{X} \rightarrow \mathrm{AlB}$ expands to $\mathrm{X} \rightarrow \mathrm{A}$ and $\mathrm{X} \rightarrow \mathrm{B}$. However, (iii) Smoldyn does not accept patterns that expand to different numbers of elementary patterns on the reactant and product sides. For example, Smoldyn rejects the reaction pattern $\mathrm{AlBlC} \rightarrow \mathrm{DIE}$

In addition to the chemical reaction equation, Smoldyn allows modelers to specify several other reaction parameters. These include the reaction rate constant, how any 
dissociation products should be arranged, whether molecule serial numbers should be retained, and others. These parameters are entered in the same way for single reactions, reactions defined using wildcards, and reactions defined as rules, described next.

\subsection{Reaction network expansion}

In most cases, Smoldyn acts on input file statements as it encounters them. For example, if Smoldyn encounters a difc statement in an input file, it immediately sets the diffusion coefficient for all species that match to the given species pattern to the given value. Likewise, if Smoldyn encounters a reaction statement, it immediately creates reactions for all currently defined species that match to the given reaction pattern. In this case, Smoldyn issues either a warning or an error if any product names arise that are not currently defined species. Smoldyn does not revisit these statements later on during the simulation.

On the other hand, if the statement is suffixed with “_rule”, such as difc_rule or reaction_rule, then Smoldyn does not act on the statement immediately but instead stores it for future use (after a little preliminary parsing). Smoldyn acts on these statements later on during rule expansion. Smoldyn supports two approaches for rule expansion. First, if it encounters an expand_rules statement in the input file (followed by "all" or a number), it expands the rules at that point. In this so-called generate-first approach (28), Smoldyn reads through the rules sequentially and acts on them using the currently defined species. In doing so, if it finds that a reaction specifies a product species that has not been defined, then Smoldyn creates the species. Smoldyn repeats this process for a user-specified number of iterations or until it has fully expanded the 
reaction network. This generate-first approach is often convenient for small reaction networks because Smoldyn displays all species and reactions before the simulation begins, making it easy to confirm that the network agrees with expectations. Second, the rules can be expanded using the on-the-fly approach (28), in which Smoldyn acts on the rules at every time step during the simulation, but only as required. In particular, Smoldyn only generates the reactions for a species once the first molecule of the species has actually arisen in the simulation. This prevents the generation of unused species and reactions, which can be a large fraction of the possible ones (29). This improves simulation efficiency for large reaction networks and can often enable simulations with infinite reaction networks (see Notes 4-6).

\subsection{Properties of new species}

As mentioned above, each Smoldyn species has several properties, including its diffusion coefficient, graphical display parameters, and set of surface interaction behaviors. Typically, one assigns these properties to all species that are defined in the input file using the difc, color, display_size, action, and rate statements, where the last two statements define molecule-surface interaction behaviors. However, if Smoldyn acts on these statements before it performs reaction network expansion (which is always the case for on-the-fly expansion), then they do not apply to any newly generated species. The rule statements described above, such as difc_rule, are one way to address this problem. An alternate and often better approach is that Smoldyn can assign species properties automatically by computing reaction product properties from the reactant properties. 
It does so using the following assumptions: $(i)$ reactants diffuse as though they are roughly spherical, (ii) reactant volumes add upon binding, and (iii) molecule diffusion coefficients scale as the inverse of the molecule's radius (22). This last assumption follows from the Stokes-Einstein equation, which appears to be reasonably accurate even within cells $(\mathbf{2 6}, \mathbf{3 0})$. These assumptions lead to the following equations for the product of the generic reaction $\mathrm{A}+\mathrm{B} \rightarrow \mathrm{AB}$ :

$$
\begin{aligned}
& r_{A B}=\sqrt[3]{r_{A}^{3}+r_{B}^{3}} \\
& D_{A B}=\left(D_{A}^{-3}+D_{B}^{-3}\right)^{-1 / 3}
\end{aligned}
$$

where $r_{A}$ and $r_{B}$ are the reactant radii and $D_{A}$ and $D_{B}$ are the reactant diffusion coefficients. Smoldyn assigns the product diffusion coefficient as $D_{A B}$ and computes the product's graphical display radius from the $r_{A B}$ equation. Next, Smoldyn computes the product's display color using a radius-weighted average of the reactant colors. For each of the red, green, and blue colors, it computes the product brightness value using

$$
v_{A B}=\frac{r_{A} v_{A}+r_{B} v_{B}}{r_{A}+r_{B}}
$$

where $v_{A}$ and $v_{B}$ are the reactant brightness values. Finally, Smoldyn determines surface interactions for products using the method that the new species behaves like the reactant that has the "greater action," where the possible actions are ordered with increasing value as: transmission, reflection, absorption, and porting (which is for hybrid simulations). For example, if a surface reflects reactant A and transmits reactant B, then reflection is the greater action, so the surface reflects product $\mathrm{AB}$.

\subsection{Symmetric species}


Reaction networks that include structurally symmetric species often include multiple reactions that form the same products, which increases the effective reaction rate. Consider the A-B-B-A complex for example (see Note 3). It can lose an A monomer from either the left or right sides, whereas the A-B-B complex can only lose an A monomer from the left side, so the former reaction should proceed twice as fast (assuming that all of these A-B bonds are chemically identical). Smoldyn accounts for this by watching for repeated reactions as it expands reaction patterns, and incrementing the associated reaction multiplicity when they arise. Smoldyn multiplies the reaction multiplicity by the requested reaction rate constant to compute the total reaction rate constant.

An exception arises to this multiplicity computation if the reaction rule for a bimolecular reaction can match to both possible orderings of a single pair of reactants. For example, the rule ${ }^{*} * \rightarrow{ }^{*}$ can match to the two reactants $\mathrm{A}$ and $\mathrm{AA}$ as either $\mathrm{A}+$ $\mathrm{AA}$ or $\mathrm{AA}+\mathrm{A}$ (see Note 5). Because these two possible reaction orderings typically reflect two different chemical bonds being formed, Smoldyn only considers one of the two orderings (the one in which the reactant's internal indices are in increasing order).

\section{Notes}

The following notes illustrate the use of wildcards for rule-based modeling using several example problems. These models, and additional files that I used for their analysis, are available in the Smoldyn download package in the subdirectory examples/S94_archive/Andrews_2017. Further information about the models is also available in this paper's online supplementary information. 


\section{Simple reaction networks with low symmetry. Reaction networks that are}

conceptually simple and have low symmetry are typically easy to define using wildcards.

This is illustrated with an example of second messenger signaling, where extracellular

"first messengers" bind to cell receptors, which then release intracellular "second

messengers" $(31,32)$. Figure 1A shows a simple model in which a transmembrane

receptor $(\mathrm{R})$ can bind an extracellular ligand $(\mathrm{L})$ and/or an intracellular messenger protein

(M); a messenger that is bound to a ligand-bound receptor gets phosphorylated (Mp), and phosphorylated messengers lose their phosphates spontaneously (such as from

unmodeled phosphatases). The network, which comprises 9 species and 10 reactions

(Figure 1B), can be expressed with the following 4 rules using wildcards:

$\begin{array}{lll}\text { rxnlr } & \left.L(\text { fsoln })+R^{*}(\text { up })<->L R^{*} \text { (up }\right) & \text { krl_on krl_off } \\ \text { rxnrm } & \left.* R(\text { up })+M^{*}(\text { bsoln })<->* R M^{*} \text { (up }\right) & \text { krm_on krm_off } \\ \text { rxnphos } & L R M(\text { up })->\operatorname{LMM}(\text { up }) & \text { k_phos } \\ \text { rxnunphos } & M p(\text { soln })->M(\text { soln }) & \text { k_unphos }\end{array}$

Each line shows the rule name, the reaction rule, and the reaction rate constants. Note that the use of wildcards, which in this case is just the '*' character, enabled each rule to represent a separate process in a clear manner. Also note that the reactant and product states (the spatial localizations given within parentheses) are straightforward to define and reasonably intuitive. Smoldyn uses them to correctly place all receptor complexes at the membrane, ligands in the extracellular space, and messengers in the cytosol (Figure 1C). 
2. More complicated networks with low symmetry. Figure 2 A shows a slightly more complicated example, but one that still includes asymmetric complexes. It shows a model of transposon excision that was developed to answer the question of how DNA transposons regulate their copy numbers so that they do not overproduce themselves and then kill their hosts (33) (transposons are mobile sections of DNA that can be amplified as they move from one location in the genome to another). In the model, the A-B species is a transposon with ends ' $\mathrm{A}$ ' and ' $\mathrm{B}$ ', and $\mathrm{T}_{2}$ is a transposase dimer, an enzyme that binds to and cuts transposon ends. The transposase can be non-specifically bound to DNA $\left(\mathrm{T}_{2, \text { nsb }}\right)$ or freely diffusing in the nucleus $\left(\mathrm{T}_{2}\right)$. At low transposase concentrations: a $\mathrm{T}_{2}$ binds to a transposon end to form a singly-bound transposon $\left(\mathrm{T}_{2} \mathrm{~A}-\mathrm{B}\right.$ or $\left.\mathrm{A}-\mathrm{BT}_{2}\right)$, this DNA forms a loop, the same $\mathrm{T}_{2}$ binds to the other transposon end $\left(\mathrm{AT}_{2} \mathrm{~B}\right)$, and the transposase cuts out the transposon (the reaction with rate $k_{3}$ ). In the model, the transposition products conserve the reactant amounts and create an X molecule as a transposition counter although, in actuality, transpositions can produce additional transposons, amplifying the transposon in the genome. At high $\mathrm{T}_{2}$ concentrations: transposases bind to singly-bound transposons to create doubly-bound transposons $\left(\mathrm{T}_{2} \mathrm{~A}-\right.$ $\mathrm{BT}_{2}$ ), which cannot undergo transposition, thereby regulating the process. This model can be expressed using wildcards as

\begin{tabular}{|c|c|c|}
\hline rxnT2nsb & $T 2<->T 2 n s b$ & $k \theta f k \theta r$ \\
\hline rxnABbind & $A-B * 1 * A-B+T 2<->T 2 A-B * \mid * A-B T 2$ & $k 1 f k 1 r$ \\
\hline rxnassemble & T2\&A-B $<->$ AT2B & $k 2 f k 2 r$ \\
\hline rxnexcise & $A T 2 B \rightarrow A-B+T 2+X$ & k3 \\
\hline
\end{tabular}


The OR operators in rxnABbind indicate that $\mathrm{T}_{2}$ can bind to either the left of A-B* $(\mathrm{A}-\mathrm{B}$ or $\left.\mathrm{A}-\mathrm{BT}_{2}\right)$ or the right of $* \mathrm{~A}-\mathrm{B}\left(\mathrm{A}-\mathrm{B}\right.$ or $\left.\mathrm{T}_{2} \mathrm{~A}-\mathrm{B}\right)$. The permutation operator in rxnassemble indicates that both $\mathrm{T}_{2} \mathrm{~A}-\mathrm{B}$ and $\mathrm{A}-\mathrm{BT} \mathrm{T}_{2}$ react to form $\mathrm{AT}_{2} \mathrm{~B}$.

Expanding these reaction rules with Smoldyn produced the reaction network shown in Figure 2A, as anticipated. The physiological rate constants (33) vary extremely widely (e.g. $k_{0 f}=10^{5} \mathrm{~s}^{-1}$ and $k_{2 f}=4 \cdot 3 \times 10^{-4} \mathrm{~s}^{-1}$ ), meaning that Smoldyn would have to use short time steps to resolve the fast reactions but also run for a very long time to observe the slow reactions, so I simulated these reactions deterministically instead using Mathematica. Figure 2B compares the simulated transposition rates with values derived from analytical theory (supplementary information), showing excellent agreement.

3. Symmetric complexes, modeled with asymmetric notation. Reaction networks that include structurally symmetric protein complexes, such as dimers and higher oligomers (34), generally require a little more care. In particular, it is often the case that a single complex can be represented correctly in multiple ways, leading to the question of whether the model notation should just include one of the ways, or all of them. Which approach is simplest depends on the specific problem; this note shows an example of the former approach, in which each complex is represented in just one way.

Figure 3A shows a simple model of reversible dimer assembly for a symmetric complex that has the form A-B-B-A, a form that is loosely based upon receptor tyrosine kinases such as the epidermal growth factor and insulin receptors (35). The model includes the monomers $\mathrm{A}$ and $\mathrm{B}$, dimers $\mathrm{AB}$ and $\mathrm{BB}$, trimer $\mathrm{ABB}$, and the tetramer 
ABBA. The notation is asymmetric in that it includes the species $\mathrm{AB}$ but not the species BA, which would be chemically identical. Similarly, it includes ABB but not BBA. It can be expressed with the reaction rules:

$\begin{array}{lll}r \times n A B \text { on } & A+B|B B| B B|A B B-A B| A B B|A B B| A B B A & A B \_0 N \\ r \times n A B \text { off } & A B|A B B| A B B A|A B B A-A+B| B B|A B B| A B B & \text { AB_OFF } \\ r \times n B B o n 1 & B+B|A B-B B| A B B & \text { BB_ON } \\ r \times n B B o n 2 & A B+A B-A B B A & \text { BB_ON } \\ r \times n B B \text { off } & * B B *-* B+* B & \text { BB_OFF }\end{array}$

These rules make heavy use of the OR operator. For example, the first reaction rule shows that $\mathrm{A}$ can bind to any of $\mathrm{B}, \mathrm{BB}, \mathrm{BB}$, or $\mathrm{ABB}$, and the products are, respectively, $\mathrm{AB}, \mathrm{ABB}, \mathrm{ABB}$, and $\mathrm{ABBA}$. The repeated $\mathrm{BB}$ reactants in this rule reflect the fact that A can bind to either the left or right side of $\mathrm{BB}$ so the rate constant for this reaction should be twice the listed value (AB_ON). Similarly, in the second reaction rule, ABBA dissociates twice to $\mathrm{A}+\mathrm{ABB}$ to reflect the two $\mathrm{A}-\mathrm{B}$ bonds in ABBA. These rules are somewhat inelegant in that they do not reflect the symmetry of the system, include strings of OR operators, and only include irreversible reactions despite the fact that the model reactions are reversible. This inelegance arises from the decision to use asymmetric notation and from limitations in the wildcard approach. Nevertheless, these rules are substantially simpler than the full list of 12 reactions.

The reaction network that Smoldyn computed from these rules was identical to ones that arose from BioNetGen and manual expansion (22), validating the rule approach. Figure 3B shows that a Smoldyn simulation that was defined with these rules agreed well 
with a deterministic simulation of the same network, computed using ordinary differential equations.

4. Symmetric complexes, modeled with symmetric notation. This note continues on the topic of symmetric complexes, but now using symmetric notation. Here, if a complex can be represented correctly in multiple ways, the approach is to not just pick one of them but to use all of them. This increases network complexity due to the greater number of species and reactions, but can simplify the reaction rules through maintenance of the network symmetry.

E. coli bacteria have several mechanisms for locating their cell division plane at the cell center, one of which is to prevent division elsewhere with the Min system $(36,37)$. Here, the combined actions of the MinD and MinE proteins create a spatiotemporal oscillation between the cell poles that keeps the co-localized MinC away from the cell center; MinC inhibits division apparatus formation, thus inhibiting cell division away from the cell center. This system has been modeled extensively $(38,39)$ but few models explicitly represent MinD or MinE dimerization (40), despite the fact that both have dissociation constants that are comparable to their intracellular concentrations $(41,42)$. Interestingly, MinD only dimerizes when bound to ATP (43) and MinD only hydrolyzes ATP when it is dimeric (44).

Figure 4A shows a model of MinD nucleotide binding and dimerization. All species are MinD proteins, but bound to different co-factors: ' $\mathrm{T}$ ' represents MinD bound to ATP, 'D' represents MinD bound to ADP, and 'A' represents MinD bound to neither ('A' stands for apo). Pairs of these symbols, such as 'TT', represent dimers. Three of the 
dimers are heterodimers that the model represents using both possible orderings, such as DT and TD. The model can be described with the following rules, of which the first three represent nucleotide substitution, and subsequent ones represent dimerization, dimer dissociation, and ATP hydrolysis:

\begin{tabular}{|c|c|c|}
\hline rxnAtoD & $* A^{*}<->* D *$ & KATOD KDTOA \\
\hline rxnAtoT & ${ }^{*} \mathrm{~A}^{*}<->* \mathrm{~T}^{*}$ & КАТОТ КТTОА \\
\hline rxnDtoT & $* \mathrm{D} *<->* \mathrm{~T}^{*}$ & KDTOT KTTOD \\
\hline rxndimer & $\mathrm{T}+\mathrm{T} \rightarrow \mathrm{TT}$ & KDIMER \\
\hline rxndissoc & $? ?->?+?$ & KDISS \\
\hline rxnhydro & $? \& \mathrm{~T}->\quad ? \& \mathrm{D}$ & KHYDRO \\
\hline
\end{tabular}

Maintaining the reaction network symmetry in the model notation enabled simple and elegant reaction rules in this case. Note the use of the '?' wildcard; for example, rxndissoc uses it to indicate that all dimers dissociate with the same rate constant. Also, use of the permutation operator in the last rule shows that any dimer with a ' $\mathrm{T}$ ' in it, regardless of whether the ' $\mathrm{T}$ ' is the first or second symbol, is able to perform hydrolysis.

Figure 4A also illustrates on-the-fly network generation for this model using background shading. It depicts the situation in which the only species that have arisen in the simulation so far are A, D, T, TT, and DT and/or TD. They are over a white background to show that this region of the network has been explored. Species and reactions in the adjacent light grey regions have been generated by Smoldyn so that they could be used, but they have not actually been used in the simulation so far. Species and 
reactions in the dark grey regions have not been generated yet (and may not require generation), which saves computation and computer memory.

Figure 4B shows the number of molecules of each species at steady-state, where the bars are from a deterministic simulation in Mathematica and the points are average values from a Smoldyn simulation. It shows that most of the MinD is bound to ATP and is either monomeric or dimeric. These results were computed from physiologically reasonable parameters for a single cell (supplementary information), but do not account for membrane or MinE interactions.

\section{Polymerization with identical monomers. Cellular polymers include $(i)$}

microtubules and actin, which are important for cell structure and intracellular transport, (ii) intermediate filaments, which provide mechanical strength, (iii) DNA and RNA, which encode genetic information, $(i v)$ polysaccharides, which provide structure and store energy, and sometimes $(v)$ amyloid fibrils, which can cause neurodegenerative diseases (45-47). Most of these polymers assemble at one or both ends, although some can also anneal, meaning that two polymers join end-to-end.

Figure 5A shows a polymer model that assembles and disassembles at one end (called "polymer_end1"). It can be expressed with the reaction rule
rxnend
$*+\mathrm{A}<->*^{*}$
KF KR

where ' $\mathrm{A}$ ' is a single polymer unit and $\mathrm{KF}$ and $\mathrm{KR}$ are the forward and reverse reaction rate constants. The isolated asterisk was adequate in this rule because this model did not include other species, but would have created unintended reactions otherwise. A 
simulation that started with 20,000 monomers and used on-the-fly expansion showed that the polymers exhibited an exponential length distribution at equilibrium, in agreement with theory (48) (Figure 5C, supplementary information). On completion, this model had 40 species and 77 reactions.

Some limitations of the method were interesting. (i) This simulation represented polymer lengths by listing their units rather than with numbers (e.g "AAA" rather than “A3”), so polymers were limited to 256 units because that is the longest species name that Smoldyn allows. (ii) Smoldyn represents these polymers as spheres rather than as extended filaments; this is clearly inaccurate for stiff polymers, although actually reasonably accurate for highly flexible polymers which tend to collapse into loose clusters (48). In the latter case, Smoldyn computes polymer radii as increasing as $L^{1 / 3}$, where $L$ is the polymer length, whereas the ideal scaling for freely jointed chains is $L^{1 / 2}$ $(47,49)$. And (iii) Smoldyn computes the polymer diffusion coefficients as decreasing as $L^{-1 / 3}$, as compared to the $L^{-0.6}$ scaling that is typically observed experimentally for polymers (47).

A more serious flaw with this model is that Smoldyn assigns the same reaction rate to all association reactions. This is the correct behavior for the given reaction rule, but does not account for the fact that the $\mathrm{A}+\mathrm{A} \rightarrow \mathrm{AA}$ reaction can happen in either of two ways: either of the two reactant monomers can end up at the "left" end of the product. The following reaction rules (model "polymer_end2") fix this flaw

rxn1 rxn2
$A+A<->A A$

${ }^{*} A A+A<->* A A A$
$2 * K F \quad K R$

KF KR 
Here, monomer association proceeds twice as fast as association of higher polymers.

Results from these latter rules agreed with a comparable model written in BNGL (22) and, at equilibrium, they also showed an exponential length distribution for all polymers with more than one monomer (see supplementary information).

Figure 5B shows a similar model, but one which represents polymers that can anneal and break (model "polymer_mid"). It can be expressed with the reaction rule

rxnmid ${ }^{*}+{ }^{*}<->* *$ 2*KF KR

As above, the association reaction rate was doubled to account for the fact that either of the two reactants can end up on the "left" side of the product. This follows from the fact that Smoldyn only considers a single ordering for any particular pair of reactants; for example, it generates the reaction $\mathrm{A}+\mathrm{AA} \rightarrow \mathrm{AAA}$ but not also $\mathrm{AA}+\mathrm{A} \rightarrow \mathrm{AAA}$. This model reached equilibrium much faster than the former ones but produced essentially the same exponential length distribution as the "polymer_end1" model (Figure 5C). This model led to a much larger reaction network, with 151 species and 4037 reactions, because each species can participate in many more reactions.

6. Polymer sequences and chemical structures. The pattern matching aspects of the wildcard method enable it to be used to define reactions that are specific to individual polymer sequences and chemical structures. These applications would be possible using BioNetGen or other rule-based modeling approaches, but would generally not be as convenient. 
The central dogma of molecular biology is that cells transcribe DNA to mRNA and then translate mRNA to protein (45). Figure 6A shows that this process can be modeled using wildcards if sequences are reasonably short. The reaction rule

$$
\text { rxnTransc Dna* -> Dna } \$ 1+\text { Rna } \$ 1 \quad \text { KTRANSC }
$$

performs transcription, where "Dna" and "Rna" are prefixes that indicate the sequence type and the " $\$ 1 "$ portions of the products show that the same text gets substituted into each one. Ideally, this rule would not only preserve the sequence, which it does, but also replace all T symbols, for DNA thymine bases, with U symbols, for RNA uracil bases. However, there is no easy way to do so with the wildcard method as it is currently designed. A wildcard approach that used regular expressions, which are more sophisticated pattern matching approaches, would solve this problem but would also be more difficult to use. The following reaction rules perform translation by modeling ribosome ("Rib") binding to the beginning of an mRNA sequence, translation of each codon, and finally dissociation of RNA, ribosome, and protein ("Prot" prefix).

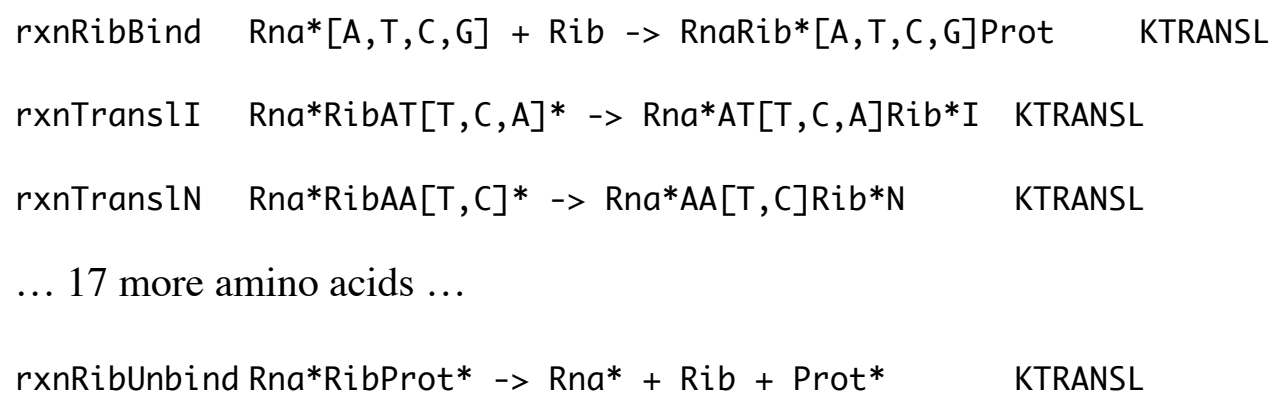


In rxnTransli reaction rule, for example, any of the RNA codons ATT, ATC, and ATA (using $\mathrm{T}$ instead of $\mathrm{U}$ ) code for isoleucine, so the product shows that the ribosome moves forward by three basepairs and an 'I', for isoleucine, is appended to the growing protein. Three final reaction rules encode for DNA mutations and RNA and protein degradation, respectively,

$\begin{array}{lll}\text { rxnMut } & \text { Dna*?* } \rightarrow \text { Dna* }\{\mathrm{A}|\mathrm{T}| \mathrm{CI} G\}^{*} & \text { KMUT } \\ \text { rxnRnaDeg } & \text { Rna*[A,T,C,G]-> } 0 & \text { KRNADEG } \\ \text { rxnProtDeg } & \text { Prot* } \rightarrow \emptyset & \text { KPROTDEG }\end{array}$

Figure $6 \mathrm{~B}$ shows results from a simulation of this model that started with one DNA molecule, DnaATCAATATT. Initially, it was transcribed to RnaATCAATATT and then translated over multiple steps to ProtINI (isoleucine-asparagine-isoleucine). At a simulation time of about 1.9 hours, the DNA mutated, leading to a slightly different RNA sequence and production of protein IYI. The protein molecule counts show a large variation because they amplify the RNA counts, which have high variation due to their low copy numbers (50).

Wildcards can also be used to define reactions based on chemical structures that are not sequence data. In particular, they are useful in conjunction with the SMILES notation (51), a scheme that allows most chemical complexes to be uniquely expressed using a single line of normal text characters (e.g. ethanol, $\mathrm{CH}_{3} \mathrm{CH}_{2} \mathrm{OH}$ is $\mathrm{CCO}$ in SMILES notation). As an example, the $E$. coli lipid synthesis pathway includes several enzymes that act repeatedly on lipids, adding a two carbon groups with each repetition (52). Each enzyme is specific to a particular chemical functional group but has low specificity with 
regard to the lipid chain length. This can be representing using wildcards starting with the 10-carbon lipid cis-3-decenoyl-ACP, written in SMILES notation as (53) $\mathrm{C}(=\mathrm{O}) \mathrm{C} / \mathrm{C}=\mathrm{C} \backslash \mathrm{CCCCCC}$. Here, $\mathrm{ACP}$ is an abbreviation for acyl carrier protein, the $\mathrm{C}(=\mathrm{O})$ portion represents a carbonyl group, the $/ \mathrm{C}=\mathrm{C} \backslash$ portion represents a cisconformation double bond, and the CCCCCC portion represents a saturated hydrocarbon tail. The reaction rules are

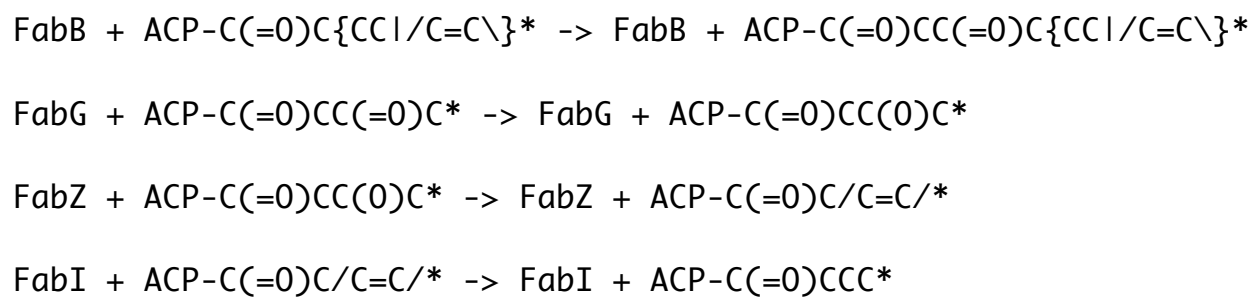

In the first reaction, FabB adds a carbonyl and extra carbon, $\mathrm{C}(=\mathrm{O}) \mathrm{C}$, to the chain. Next, FabG reduces the newly added carbonyl to a hydroxyl, $\mathrm{C}(\mathrm{O})$; FabZ reduces the hydroxyl to a trans-conformation carbon-carbon double bond, $/ \mathrm{C}=\mathrm{C} /$; and then $\mathrm{FabI}$ reduces the double bond to a single bond, CC. The end result is that the cis-3-decenoyl-ACP gets lengthened by two carbons to cis-3-dodecenoyl-ACP. Application of these rules to this longer lipid adds yet more carbons.

Both the nucleic acid sequence model and this lipid synthesis model would undoubtedly be simpler and more generalizable if they were developed using software designed specifically for the tasks. However, the fact that they can be developed using wildcards shows the method's versatility.

\section{Acknowledgement}


I thank Ronnie Chalmers, Akintunde Emiola, Jim Faeder, and Karen Lipkow for useful discussions. Much of this work was carried out during a visit to the Isaac Newton Institute for Mathematical Sciences, for which I thank Radek Erban, David Holcman, Sam Isaacson, and Konstantinos Zygalakis, who were the program organizers, and the Institute Staff. I also thank Roger Brent, Erick Matsen, and Harlan Robbins for providing space for me at the FHCRC, where the work was completed. This work was supported by a Simons Foundation grant awarded to SSA and by EPSRC grant EP/K032208/1 awarded to the Isaac Newton Institute.

\section{References}

1. Boyle, R. (1661) The Sceptical Chymist, F. Cadwell, London.

2. Waage, P., and Guldberg, C. M. (1864) Studier over affiniteten Forhandlinger: Videnskabs-Selskabet i Christiania, 35-40.

3. Michaelis, L., and Menten, M. L. (1913) Die kinetik der invertinwirkung Biochem. Z. 49, 333-69.

4. Gibbs, J. W. (1875-1878) On the equilibrium of heterogeneous substances Transactions of the Connecticut Academy 3, 108-248, 343-524.

5. Jaynes, E. T. (1992) The Gibbs paradox in Maximum Entropy and Bayesian Methods (Smith, C. R., Erickson, G. J., and Neudorfer, P. O., Eds.), pp. 1-22, Kluwer Academic Publishers, Dordrecht, Holland.

6. Alves, R., Antunes, F., and Salvador, A. (2006) Tools for kinetic modeling of biochemical networks Nat. Biotechnol. 24, 667-72. 
7. Andrews, S. S., Dinh, T., and Arkin, A. P. (2009) Stochastic models of biological processes in Encyclopedia of Complexity and System Science (Meyers, R. A., Ed.), Vol. 9, pp. 8730-49, Springer, New York.

8. Bray, D., and Lay, S. (1997) Computer-based analysis of the binding steps in protein complex formation Proc. Natl. Acad. Sci. USA 94, 13493-98.

9. Goldman, J., Andrews, S. S., and Bray, D. (2004) Size and composition of membrane protein clusters predicted by Monte Carlo analysis Eur. Biophys. J. 33, 506-12.

10. Sneddon, M. W., Faeder, J. R., and Emonet, T. (2011) Efficient modeling, simulation and coarse-graining of biological complexity with NFsim Nat. Methods 8, 177-83.

11. Gruenert, G., Ibrahim, B., Lenser, T., Lohel, M., Hinze, T., and Dittrich, P. (2010) Rule-based spatial modeling with diffusing, geometrically constrained molecules BMC Bioinf. 11, 307.

12. Schöneberg, J., and Noé, F. (2013) RadDDy - A software for particle-based reactiondiffusion dynamics in crowded cellular environments PLOS ONE 8, e74261.

13. Morton-Firth, C. J., and Bray, D. (1998) Predicting temporal fluctuations in an intracellular signalling pathway J. Theor. Biol. 192, 117-28.

14. Bittig, A. T., Haack, F., Maus, C., and Uhrmacher, A. M. (2011) Adapting rule-based model descriptions for simulating in continuous and hybrid space in Proceedings of the 9th International Conference on Computational Methods in Systems Biology, pp. 161-70, ACM.

15. Stefan, M. I., Bartol, T. M., Sejnowski, T. J., and Kennedy, M. B. (2014) Multi-state modeling of biomolecules PLoS Comp. Biol. 10, e1003844. 
16. Andrews, S. S., Addy, N. J., Brent, R., and Arkin, A. P. (2010) Detailed simulation of cell biology with Smoldyn 2.1 PLoS Comp. Biol. 6, e1000705.

17. Tolle, D. P., and Le Novère, N. (2010) Meredys, a multi-compartment reactiondiffusion simulator using multistate realistic molecular complexes BMC Systems Biol. 4,24 .

18. Hlavacek, W. S., Faeder, J. R., Blinov, M. L., Posner, R. G., Hucka, M., and Fontana, W. (2006) Rules for modeling signal-transduction systems Sci. STKE 2006, re6.

19. Blinov, M. L., Faeder, J. R., Goldstein, B., and Hlavacek, W. S. (2004) BioNetGen: software for rule based modeling of signal transduction based on the interactions of molecular domains Bioinformatics 20, 3289-91.

20. Lok, L., and Brent, R. (2005) Automatic generation of cellular reaction networks with Molecularizer 1.0 Nat. Biotech. 23, 131-36.

21. Danos, V., Feret, J., Fontana, W., Harmer, R., Hayman, J., Krivine, J., ThompsonWalsh, C., and Winskel, G. (2012) Graphs, rewriting, and pathway reconstruction for rule-based models in LIPIcs-Leibniz International Proceedings in Informatics, Vol. 18, Schloss Dagstuhl-Leibniz-Zentrum fuor Informatik.

22. Andrews, S. S. (2016) Smoldyn: particle-based simulation with rule-based modeling, improved molecular interaction, and a library interface Bioinformatics accepted.

23. Andrews, S. S., and Bray, D. (2004) Stochastic simulation of chemical reactions with spatial resolution and single molecule detail Phys. Biol. 1, 137-51.

24. Andrews, S. S. (2009) Accurate particle-based simulation of adsorption, desorption, and partial transmission Phys. Biol. 6, 46015. 
25. Faeder, J. R., Blinov, M. L., and Hlavacek, W. S. (2009) Rule-based modeling of biochemical systems with BioNetGen Methods in Molecular Biology, Systems Biology 500, 113-67.

26. Andrews, S. S. (2012) Spatial and stochastic cellular modeling with the Smoldyn simulator Methods in Molecular Biology 804, 519-42.

27. Bardwell, L. (2005) A walk-through of the yeast mating pheromone response pathway Peptides 26, 339-50.

28. Blinov, M. L., Faeder, J. R., Yang, J., Goldstein, B., and Hlavacek, W. S. (2005) 'Onthe-fly' or 'generate-first' modeling? Nat. Biotechnol. 23, 1344-45.

29. Suderman, R., and Deeds, E. J. (2013) Machines vs. ensembles: effective MAPK signaling through heterogeneous sets of protein complexes PLoS Comp. Biol.9, e1003278.

30. Dix, J. A., and Verkman, A. S. (2008) Crowding effects on diffusion in solutions and cells Ann. Rev. Biophys. 37, 247-63.

31. Alberts, B., Johnson, A., Lewis, J., Raff, M., Robers, K., and Walter, P. (2008) Molecular Biology of the Cell, Garland Science, New York.

32. Sutherland, E. W., I., O., and Butcher, R. W. (1964) The action of epinephrine and the role of the adenyl cyclase system in hormone action Recent Progress in Hormone Research 21, 623-46.

33. Claeys Bouuaert, C., Lipkow, K., Andrews, S. S., Liu, D., and Chalmers, R. (2013) The autoregulation of a eukaryotic DNA transposon eLife 2, e00668.

34. Marianayagam, N. J., Sunde, M., and Matthews, J. M. (2004) The power of two: protein dimerization in biology TRENDS Biochem. Sci. 29, 618-25. 
35. Hubbard, S. R., and Till, J. H. (2000) Protein tyrosine kinase structure and function Ann. Rev. Biochem. 69, 373-98.

36. Lutkenhaus, J. (2007) Assembly and dynamics of the bacterial MinCDE system and spatial regulation of the $\mathrm{Z}$ ring Ann. Rev. Biochem. 76, 539-62.

37. Loose, M., Kruse, K., and Schwille, P. (2011) Protein self-organization: lessons from the Min system Ann. Rev. Biophys. 40, 315-36.

38. Howard, M., and Kruse, K. (2005) Cellular organization by self-organization: mechanisms and models for Min protein dynamics J. Cell. Biol. 168, 533-36.

39. Kruse, K., Howard, M., and Margolin, W. (2007) An experimentalist's guide to computational modelling of the Min system Mol. Microbiol. 63, 1279-84.

40. Cytrynbaum, E., and Marshall, B. D. L. (2007) A multi-stranded polymer model explains MinDE dynamics in E. coli cell division Biophys. J. 93, 1134-50.

41. Zhang, Y., Rowland, S., King, G., Braswell, E., and Rothfield, L. (1998) The relationship between hetero-oligomer formation and function of the topological specificity domain of the Escherichia coli MinE protein Mol. Microbiol. 30, 265-73.

42. Hu, Z., and Lutkenhaus, J. (2003) A conserved sequence at the C-terminus of MinD is required for binding to the membrane and targeting MinC to the septum Mol. Microbiol. 47, 345-55.

43. Hu, Z., Saez, C., and Lutkenhaus, J. (2003) Recruitment of MinC, an inhibitor of Zring formation, to the membrane in Escherichia coli: role of MinD and MinE J. Bact. 185, 196-203.

44. Andrews, S. S., Moghaddam, A., and Groves, J. T. (2006) in "American Chemical Society", San Francisco, CA. 
45. Alberts, B., Bray, D., Lewis, J., Raff, M., Roberts, K., and Watson, J. D. (1994) Molecular Biology of the Cell, Garland Publishing, New York.

46. Ross, C. A., and Poirier, M. A. (2005) What is the role of protein aggregation in neurodegeneration? Nat. Rev. Mol. Cell Biol. 6, 891-98.

47. Andrews, S. S. (2014) Physical models and computational methods for modeling cytoskeletal and DNA filaments Phys. Biol. 11, 011001.

48. Flory, P. J. (1953) Principles of Polymer Chemistry, Cornell University Press, Ithaca, NY.

49. Doi, M., and Edwards, S. F. (1986) The Theory of Polymer Dynamics, Oxford University Press, Oxford.

50. Berg, O. G. (1978) A model for the statistical fluctuations of protein numbers in a microbial population J. Theor. Biol. 71, 587-603.

51. Weininger, D. (1988) SMILES, a chemical language and information system. 1. Introduction to methodology and encoding rules J. Chem. Inf. Comput. Sci. 28, 31-36.

52. Emiola, A., Andrews, S. S., Heller, C., and George, J. (2016) Crosstalk between the lipopolysaccharide and phospholipid pathways during outer membrane biogenesis in Escherichia coli Proc. Natl. Acad. Sci. USA 113, 3108-13.

53. MacPhee, D. J. (2010) Methodological considerations for improving Western blot analysis J. Pharmacological and Toxicological Methods 61, 171-77. 


\section{Tables}

Table 1. Smoldyn wildcards

\begin{tabular}{|c|c|c|c|}
\hline symbol & meaning & matching example & reaction example \\
\hline$?$ & any 1 character & $\mathrm{A}$ ? matches to $\mathrm{AB}, \mathrm{AC}$, etc. & $\mathrm{A} ? \rightarrow \mathrm{B} ?$ \\
\hline$*$ & 0 or more characters & $\mathrm{A}^{*}$ matches to $\mathrm{A}, \mathrm{AB}$, etc. & $\mathrm{A}^{*} \rightarrow \mathrm{B}^{*}$ \\
\hline$[\ldots]$ & 1 listed character & $\mathrm{A}[\mathrm{a}-\mathrm{c}]$ matches to $\mathrm{Aa}, \mathrm{Ab}, \mathrm{Ac}$ & $\mathrm{A}[\mathrm{u}, \mathrm{p}] \rightarrow \mathrm{B}[0,1]$ \\
\hline । & OR operator & $\mathrm{A}|\mathrm{B}| \mathrm{C}$ matches to $\mathrm{A}, \mathrm{B}, \mathrm{C}$ & $\mathrm{AlB} \rightarrow \mathrm{alb}$ \\
\hline$\&$ & permutation & $\mathrm{A} \& \mathrm{~B}$ matches to $\mathrm{AB}, \mathrm{BA}$ & $\mathrm{A} \& \mathrm{~B} \rightarrow \mathrm{a} \& \mathrm{~b}$ \\
\hline$\{\ldots\}$ & grouping & $\mathrm{A}\{\mathrm{B} \mid \mathrm{C}\}$ matches to $\mathrm{AB}, \mathrm{AC}$ & $\mathrm{A}\{\mathrm{b} \mid \mathrm{c}\} \rightarrow \mathrm{A}\{\mathrm{clb}\}$ \\
\hline$\$ n$ & $n$ 'th match & not applicable & $\mathrm{A} ? ? \rightarrow \mathrm{B} \$ 2 \$ 1$ \\
\hline
\end{tabular}




\section{Figure captions}

Figure 1. Model of second messenger signaling. (A) Cartoon of the model, showing the components and their interactions. (B) The complete reaction network, where species are shown with the same colors as those generated by Smoldyn. (C) Snapshot of this model simulated in Smoldyn, again using the same color scheme. The line across the middle represents the membrane, the region above the line is the extracellular region, and the region below the line is the cytoplasm.

Figure 2. Model of transposase dynamics modified from ref. (33). (A) Reaction network, where A-B is a transposon and $\mathrm{T}_{2}$ is a transposase dimer. Colors are those generated by Smoldyn. (B) Transposition rate for a single transposon as a function of the total transposase dimer concentration within the nucleus. Points represent simulation data generated with ordinary differential equations and simulated in Mathematica and the line represents an analytical theory for the transposition rate (supplementary information).

Figure 3. Model of symmetric complexation using asymmetric notation. (A) Reaction network for binding between $\mathrm{A}$ and $\mathrm{B}$ components that can assemble into the A-B-B-A complex. (B) Black lines show reaction kinetics computed from manual reaction network expansion and simulated with ordinary differential equations using Mathematica; colored points show reaction kinetics from Smoldyn's expansion of wildcard rules and then simulation. Colors in both panels are those generated by Smoldyn. Simulation parameters: $A B_{-} \_N=10, A B \_O F F=0.05, B B_{-} O N=8, B B \_0 F F=0.03$, 
10,000 initial A molecules, 10,000 initial B molecules, volume of $100^{3}$, time from 0 to 20 with steps, in Smoldyn simulation, of 0.05.

Figure 4. Model of E. coli MinD dimerization and nucleotide binding. (A) Reaction network. Background shading illustrates on-the-fly simulation for a simulation in which A, D, T, TT, and either DT or TD have arisen. White regions are explored, light grey are generated by not explored, and dark grey are not generated; see the main text. (B) Species abundance in a single cell at steady-state using physiologically reasonable parameter estimates. Bars are deterministic values computed by simulating the network in Mathematica using ordinary differential equations and points are averages of Smoldyn simulation values $(n=20)$. Parameters are listed in the supplementary information.

Figure 5. Models of polymerization. (A) Reaction network for polymers that can add or lose units from a single end. (B) Part of a reaction network for polymers that can add or lose units from their ends, and can also break and anneal. (C) Equilibrium length distributions of polymers from a simulation of the end-polymerization model ("polymer_end1" model, red points), a simulation of the breaking and annealing model ("polymer_mid" model, blue points), and analytical theory (solid black line). Dashed lines show the theoretical standard deviations.

Figure 6. Model of DNA transcription and then RNA translation. (A) Diagram of the model, showing some of the species that arose during a particular simulation run that used on-the-fly network expansion. The starting DNA sequence is shown in black and 
bold face. It could mutate to other sequences, shown above and below in black. It was also transcribed to RNA, shown in red, and these RNAs were translated one codon at a time to produce the polypeptide ProtINI, shown in green. Mutation actually happened at simulation time of about 1.9 hours, at which point the new DNA was transcribed to the RNA shown in orange and it was translated to the protein shown in blue. (B) Copy numbers of the RNA and protein molecules from the same simulation, using the same colors as panel A. 
bioRxiv preprint doi: https://doi.org/10.1101/112052; this version posted February 27, 2017. The copyright holder for this preprint (which was not certified by peer review) is the author/funder, who has granted bioRxiv a license to display the preprint in perpetuity. It is made available under aCC-BY 4.0 International license.

\section{Figure 1}
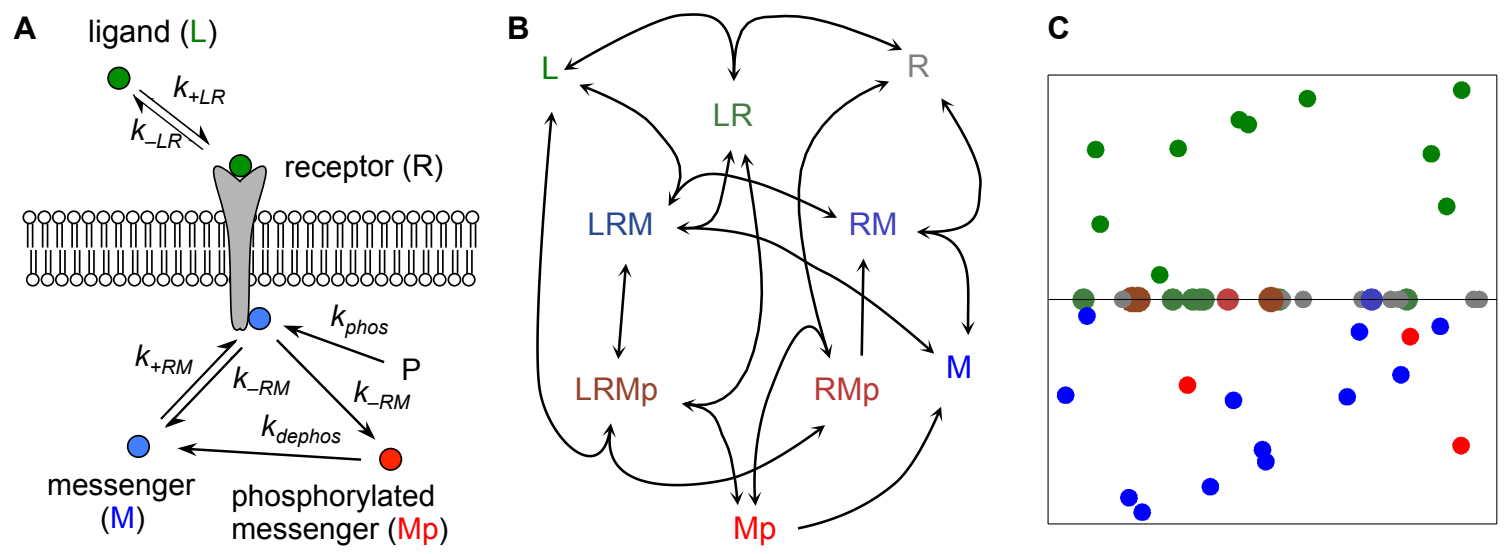
bioRxiv preprint doi: https://doi.org/10.1101/112052; this version posted February 27, 2017. The copyright holder for this preprint (which was not certified by peer review) is the author/funder, who has granted bioRxiv a license to display the preprint in perpetuity. It is made available under aCC-BY 4.0 International license.

Figure 2
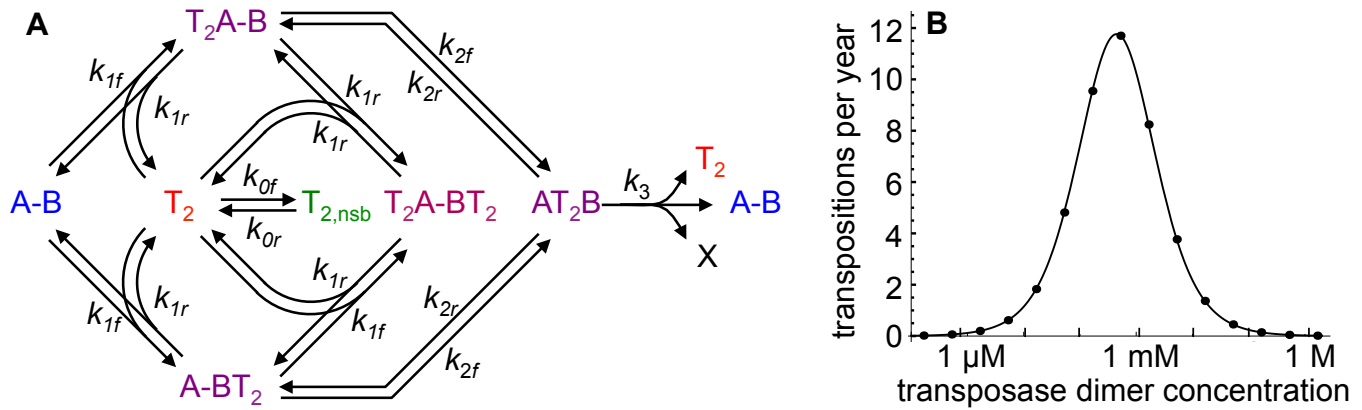
bioRxiv preprint doi: https://doi.org/10.1101/112052; this version posted February 27, 2017. The copyright holder for this preprint (which was not certified by peer review) is the author/funder, who has granted bioRxiv a license to display the preprint in perpetuity. It is made available under aCC-BY 4.0 International license.

Figure 3

A

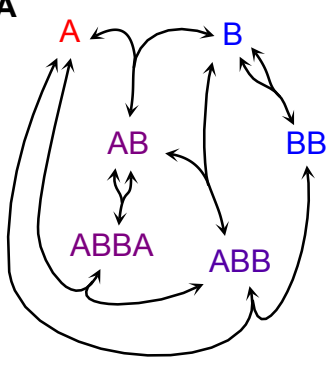

B

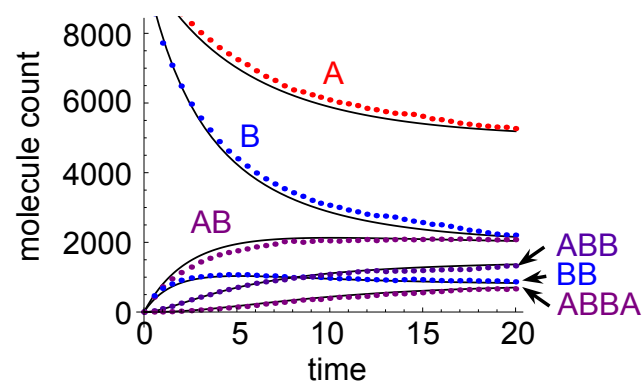


bioRxiv preprint doi: https://doi.org/10.1101/112052; this version posted February 27, 2017. The copyright holder for this preprint (which was not certified by peer review) is the author/funder, who has granted bioRxiv a license to display the preprint in perpetuity. It is made available under aCC-BY 4.0 International license.

Figure 4
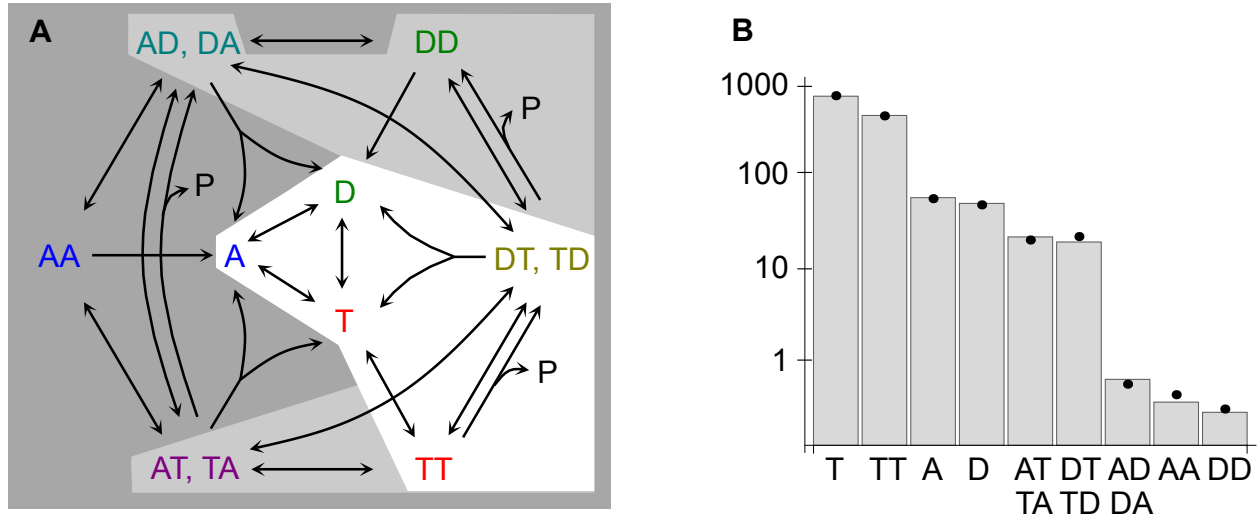
bioRxiv preprint doi: https://doi.org/10.1101/112052; this version posted February 27, 2017. The copyright holder for this preprint (which was not certified by peer review) is the author/funder, who has granted bioRxiv a license to display the preprint in perpetuity. It is made available under aCC-BY 4.0 International license.

Figure 5

A

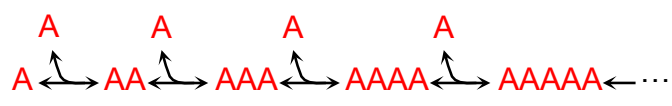

B

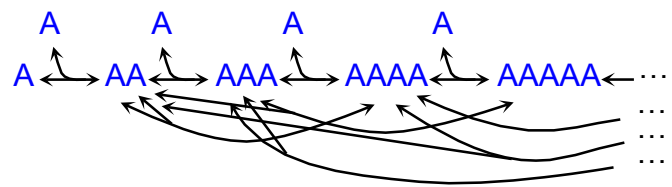

C

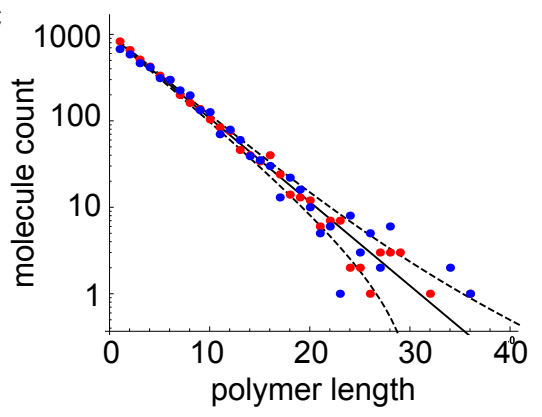




\section{Figure 6}

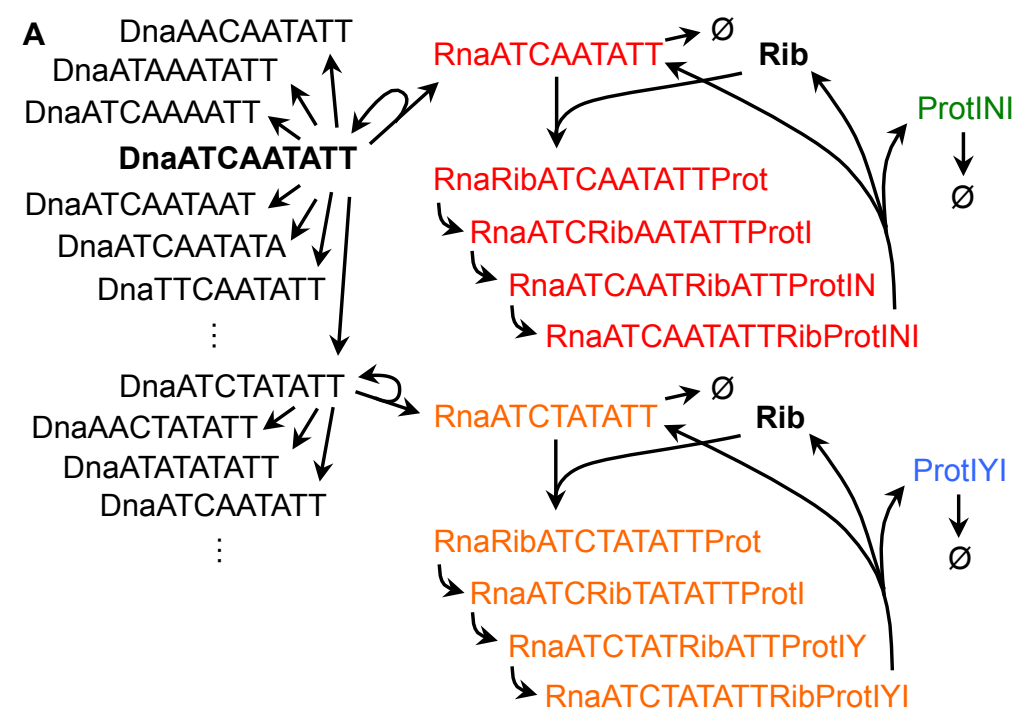

B

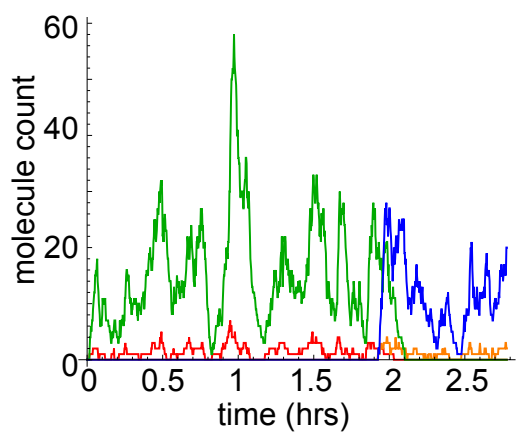




\section{Supplementary Information}

\section{Rule-based modeling using wildcards}

Steven S. Andrews

1. Second messenger signaling $\quad 2$

2. Transposon dynamics 4

3. Complexation of ABBA structure 8

4. MinD dimerization 9

5. Polymerization 12

6. Transcription and translation $\quad 19$

7. References 22 


\section{Second messenger signaling}

\section{$\underline{\text { Smoldyn input file }}$}

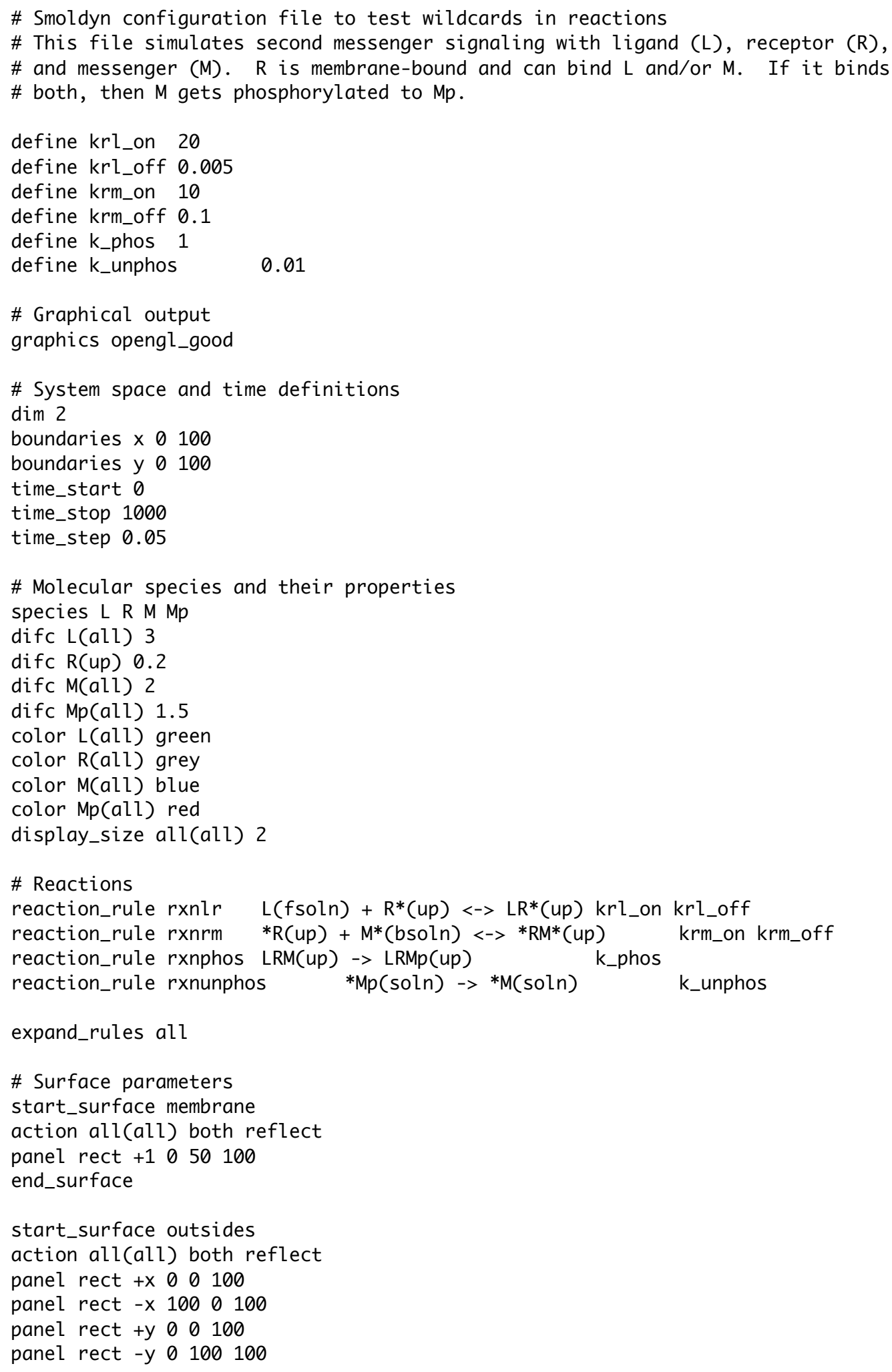


bioRxiv preprint doi: https://doi.org/10.1101/112052; this version posted February 27, 2017. The copyright holder for this preprint (which was not certified by peer review) is the author/funder, who has granted bioRxiv a license to display the preprint in perpetuity. It is made available under aCC-BY 4.0 International license.

\author{
end_surface \\ \# initial molecules \\ surface_mol 20 R(up) membrane all all \\ mol 20 L 5080 \\ mol 20 M 5020 \\ \#text_display time Mp $M^{*} L^{*}(a l l)$ \\ end_file
}




\section{Transposon dynamics}

\section{Model parameters}

Model parameters were the values determined for the in vivo situation from ref. (1). They are:

$\begin{array}{llll}\text { parameter } & \text { symbol } & \text { value } & \text { time constant } \\ \text { nucleus volume } & V & 500 \mu \mathrm{m}^{3} & \\ \text { non-specific binding sites } & n_{n s b} & 6 \times 10^{9} & \\ \text { non-specific association rate } & k_{0 f} & 5.0 \times 10^{6} \mathrm{M}^{-1} \mathrm{~s}^{-1}=0.0084 \mu \mathrm{m}^{3} \mathrm{~s}^{-1} & \\ \text { effective non-specific association rate } & k_{0 f} & 1.0 \times 10^{5} \mathrm{~s}^{-1}=k_{0 f} n_{n s b} / V & \tau_{0 f}=1.0 \times 10^{-5} \mathrm{~s} \\ \text { non-specific dissociation rate } & k_{0 r} & 139 \mathrm{~s}^{-1} & \tau_{0 r}=0.0072 \mathrm{~s} \\ \text { specific association rate } & k_{l f} & 1.9 \times 10^{8} \mathrm{M}^{-1} \mathrm{~s}^{-1}=0.32 \mu \mathrm{m}^{3} \mathrm{~s}^{-1} & \\ \text { specific dissociation rate } & k_{l r} & 1.2 \times 10^{2} \mathrm{~s}^{-1} & \tau_{l r}=0.008 \mathrm{~s} \\ \text { transposase second binding rate } & k_{2 f} & 4.3 \times 10^{-4} \mathrm{~s}^{-1} & \tau_{2 f}=2325 \mathrm{~s} \\ \text { transposase second dissociation rate } & k_{2 r} & 10^{-10} \mathrm{~s}^{-1} & \tau_{2 r}=10^{10} \mathrm{~s} \\ \text { transposition rate } & k_{3} & 1.4 \times 10^{-3} \mathrm{~s}^{-1} & \tau_{3}=714 \mathrm{~s} \\ \text { transposase diffusion coefficient } & D_{p} & 15 \mu \mathrm{m}^{2} \mathrm{~s}^{-1} & \\ \text { DNA "segmental” diffusion coefficient } & D_{s} & 5 \times 10^{-4} \mu \mathrm{m}^{2} \mathrm{~s}^{-1} & \end{array}$

\section{Analytical model}

The above table shows that the reaction time constants, which are the inverse of the reaction rate constants, vary over 15 orders of magnitude. This suggests the possibility of simplifying the model by separating the fast processes from the slow ones, and treating the fast ones as though they are at equilibrium. Indeed, this approach works well here because reactions 0 and 1 , which interconnect the group of species $\mathrm{T}_{2, \mathrm{nsb}}, \mathrm{T}_{2}, \mathrm{~A}-\mathrm{B}, \mathrm{T}_{2} \mathrm{~A}-\mathrm{B}$, $\mathrm{A}-\mathrm{BT}_{2}$, and $\mathrm{T}_{2} \mathrm{~A}-\mathrm{BT}_{2}$, are much faster than reaction 2 , which leads out of this group, to $\mathrm{AT}_{2} \mathrm{~B}$. Thus, assume that this group of species is at equilibrium.

$\mathrm{T}_{2, \mathrm{nsb}}$ is

Focus first on reaction 0 . At equilibrium, the concentration ratio between $\mathrm{T}_{2}$ and

$$
\frac{\left[\mathrm{T}_{2, \mathrm{nsb}}\right]}{\left[\mathrm{T}_{2}\right]}=\frac{k_{0 f}}{k_{0 r}} \approx \frac{1 \times 10^{5} \mathrm{~s}^{-1}}{139 \mathrm{~s}^{-1}}=720
$$

This shows that 720 times as much transposase is non-specifically bound than is freely diffusing. With the assumption that there are many fewer transposons than total transposase dimers, then an insignificant number of transposases will be bound to transposons. Define $\left[\mathrm{T}_{2, \text { total }}\right]$ as the sum of the non-specifically bound and freely diffusing transposase dimer concentrations, $\left[\mathrm{T}_{2, \mathrm{nsb}}\right]+\left[\mathrm{T}_{2}\right]$, which is a close approximation to the actual total transposase dimer concentration. Using this, the fraction of total transposase that is freely diffusing can be approximated as

$$
\frac{\left[\mathrm{T}_{2}\right]}{\left[\mathrm{T}_{2 . \text { total }}\right]}=\frac{\left[\mathrm{T}_{2}\right]}{\left[\mathrm{T}_{2 . \text { nsb }}\right]+\left[\mathrm{T}_{2}\right]}=\frac{\left[\mathrm{T}_{2}\right] /\left[\mathrm{T}_{2 . n s b}\right]}{1+\left[\mathrm{T}_{2}\right] /\left[\mathrm{T}_{2 . \text { nsb }}\right]}=\frac{k_{0 r} / k_{0 f}}{1+k_{0 r} / k_{0 f}}=\frac{k_{0 r}}{k_{0 f}+k_{0 r}} \approx 0.0014
$$


Focus next on reaction 1. At equilibrium, the following concentration ratios are equal to each other and can be given in terms of $k_{l f}$ and $k_{l r}$,

$$
\begin{aligned}
\frac{\left[\mathrm{T}_{2} \mathrm{~A}-\mathrm{B}\right]}{\left[\mathrm{T}_{2}\right][\mathrm{A}-\mathrm{B}]} & =\frac{\left[\mathrm{A}-\mathrm{BT}_{2}\right]}{\left[\mathrm{T}_{2}\right][\mathrm{A}-\mathrm{B}]}=\frac{\left[\mathrm{T}_{2} \mathrm{~A}-\mathrm{BT}_{2}\right]}{\left[\mathrm{T}_{2}\right]\left[\mathrm{T}_{2} \mathrm{~A}-\mathrm{B}\right]}=\frac{\left[\mathrm{T}_{2} \mathrm{~A}-\mathrm{BT}_{2}\right]}{\left[\mathrm{T}_{2}\right]\left[\mathrm{A}-\mathrm{BT}_{2}\right]}=\frac{k_{1 f}}{k_{1 r}} \\
& \approx \frac{1.9 \times 10^{8} \mathrm{M}^{-1} \mathrm{~s}^{-1}}{1.2 \times 10^{2} \mathrm{~s}^{-1}}=1.6 \times 10^{6} \mathrm{M}^{-1}
\end{aligned}
$$

Define the association constant $K$ as

$$
K=\frac{k_{0 r} k_{1 f}}{\left(k_{0 r}+k_{0 f}\right) k_{1 r}} \approx 2240 \mathrm{M}^{-1}
$$

The inverse of $K$, which is about $500 \mu \mathrm{M}$, is a dissociation constant equal to [A$\mathrm{B}]\left[\mathrm{T}_{2, \text { total }}\right] /\left[\mathrm{T}_{2} \mathrm{~A}-\mathrm{b}\right]$; it is the total transposase dimer concentration at which there are equal concentrations of transposon in the unbound state $A-B$ as in the singly bound state $\mathrm{T}_{2} \mathrm{~A}-\mathrm{B}$. Also define the transposon concentration sum as

$$
\left[\mathrm{A}-\mathrm{B}_{\text {sum }}\right]=[\mathrm{A}-\mathrm{B}]+\left[\mathrm{T}_{2} \mathrm{~A}-\mathrm{B}\right]+\left[\mathrm{A}-\mathrm{BT}_{2}\right]+\left[\mathrm{T}_{2} \mathrm{~A}-\mathrm{BT}_{2}\right]
$$

This is close to the total transposon concentration, except that it ignores the concentration of transposons in the $\mathrm{AT}_{2} \mathrm{~B}$ state. These are not necessarily negligible because reaction 3 is slow. The fraction of transposons in each binding state can be computed by combining the above equations, giving

$$
\begin{aligned}
& \frac{[\mathrm{A}-\mathrm{B}]}{\left[\mathrm{A}-\mathrm{B}_{\text {sum }}\right]}=\frac{1}{1+2 K\left[\mathrm{~T}_{2, \text { tot. }}\right]+K^{2}\left[\mathrm{~T}_{2, \text { tot. }}\right]^{2}} \\
& \frac{\left[\mathrm{T}_{2} \mathrm{~A}-\mathrm{B}\right]}{\left[\mathrm{A}-\mathrm{B}_{\text {sum }}\right]}=\frac{\left[{\left.\mathrm{A}-\mathrm{BT}_{2}\right]}\left[\mathrm{A}-\mathrm{B}_{\text {sum }}\right]\right.}{1+2 K\left[\mathrm{~T}_{2, \text { tot. }}\right]+K^{2}\left[\mathrm{~T}_{2, \text { tot. }}\right]^{2}} \\
& \frac{\left[\mathrm{T}_{2}{\left.\mathrm{~A}-\mathrm{BT}_{2}\right]}^{2}\right.}{\left[\mathrm{A}-\mathrm{B}_{\text {sum }}\right]}=\frac{K^{2}\left[\mathrm{~T}_{2, \text { tot. }}\right]^{2}}{1+2 K\left[\mathrm{~T}_{2, \text { tot. }}\right]+K^{2}\left[\mathrm{~T}_{2, \text { tot. }}\right]^{2}}
\end{aligned}
$$

Finally focus on reactions 2 and 3 . The concentration of $\mathrm{AT}_{2} \mathrm{~B}$ can be computed by setting its rate equation to 0 ,

$$
\begin{aligned}
& 0=\frac{d\left[\mathrm{AT}_{2} \mathrm{~B}\right]}{d t}=k_{2 f}\left(\left[\mathrm{~T}_{2} \mathrm{~A}-\mathrm{B}\right]+\left[\mathrm{A}-\mathrm{BT}_{2}\right]\right)-\left[\mathrm{AT}_{2} \mathrm{~B}\right]\left(2 k_{2 r}+k_{3}\right) \\
& {\left[\mathrm{AT}_{2} \mathrm{~B}\right]=\frac{k_{2 f}}{2 k_{2 r}+k_{3}}\left(\left[\mathrm{~T}_{2} \mathrm{~A}-\mathrm{B}\right]+\left[\mathrm{A}-\mathrm{BT}_{2}\right]\right)}
\end{aligned}
$$

If $k_{3}>>k_{2 f}$, then this concentration is negligible when compared to the total transposon concentration. However, this condition does not hold well for the parameters given above, where $k_{3}$ is only about 3 times larger than $k_{2 f}$. Thus, the total transposon concentration needs to be computed. Defining it as $\left[A-B_{\text {tot. }}\right]$, it is $\left[A-B_{\text {sum }}\right]+\left[\mathrm{AT}_{2} \mathrm{~B}\right]$. So, 
add $\left[A-B_{\text {sum }}\right]$ to each side of the above equation, substitute in for the singly-bound transposon concentrations, and simplify, to get

$$
\frac{\left[\mathrm{A}-\mathrm{B}_{\text {tot. }}\right]}{\left[\mathrm{A}-\mathrm{B}_{\text {sum }}\right]}=\frac{2 k_{2 f} K\left[\mathrm{~T}_{2, \text { tot. }}\right]}{\left(2 k_{2 r}+k_{3}\right)\left(1+2 K\left[\mathrm{~T}_{2, \text { tot. }}\right]+K^{2}\left[\mathrm{~T}_{2, \text { tot. }}\right]^{2}\right)}+1
$$

Next, use the fact that reaction 2 is upstream of reaction 3 and has a negligible reverse reaction rate, so its rate is the transposition rate. In other words, any transposon that undergoes reaction 2 will almost certainly go on to transposition, so the rate of reaction 2 is the rate of transposition. Define the rate of reaction 2 as $\phi$, for the transposition flux, which is

$$
\phi=k_{2 f}\left[\mathrm{~T}_{2} \mathrm{~A}-\mathrm{B}\right]+k_{2 f}\left[\mathrm{~A}-\mathrm{BT}_{2}\right]
$$

Substituting in the above values gives

$$
\phi=\frac{2 k_{2 f} K\left[\mathrm{~T}_{2, \text { tot. }}\right]\left[\mathrm{A}-\mathrm{B}_{\text {tot. }}\right]}{1+2 K\left[\mathrm{~T}_{2, \text { tot. }}\right]+K^{2}\left[\mathrm{~T}_{2, \text { tot. }}\right]^{2}}\left[\frac{2 k_{2 f} K\left[\mathrm{~T}_{2, \text { tot. }}\right]}{\left(2 k_{2 r}+k_{3}\right)\left(1+2 K\left[\mathrm{~T}_{2, \text { tot. }}\right]+K^{2}\left[\mathrm{~T}_{2, \text { tot. }}\right]^{2}\right)}+1\right]^{-1}
$$

The final term can be neglected if $k_{3} \gg k_{2 f}$. This final result is the transposition rate as a function of the transposase dimer concentration. For the most part, it depends only on the rate of DNA ring closing, which is $k_{2 f}$, and on the association constant for transposase onto transposons, which is $K$.

\section{Smoldyn input file}

This file was only used to verify that the reaction network that was defined using wildcards exactly matched the one that was created manually. The Smoldyn simulation proceeded too slowly for it to be practical.

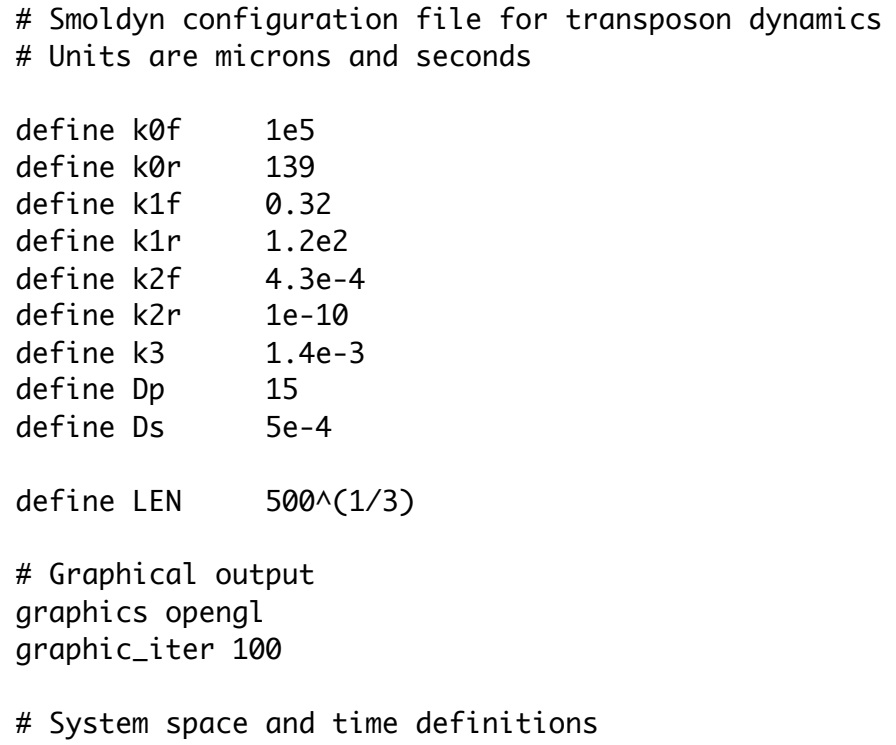


bioRxiv preprint doi: https://doi.org/10.1101/112052; this version posted February 27, 2017. The copyright holder for this preprint (which was not certified by peer review) is the author/funder, who has granted bioRxiv a license to display the preprint in perpetuity. It is made available under aCC-BY 4.0 International license.

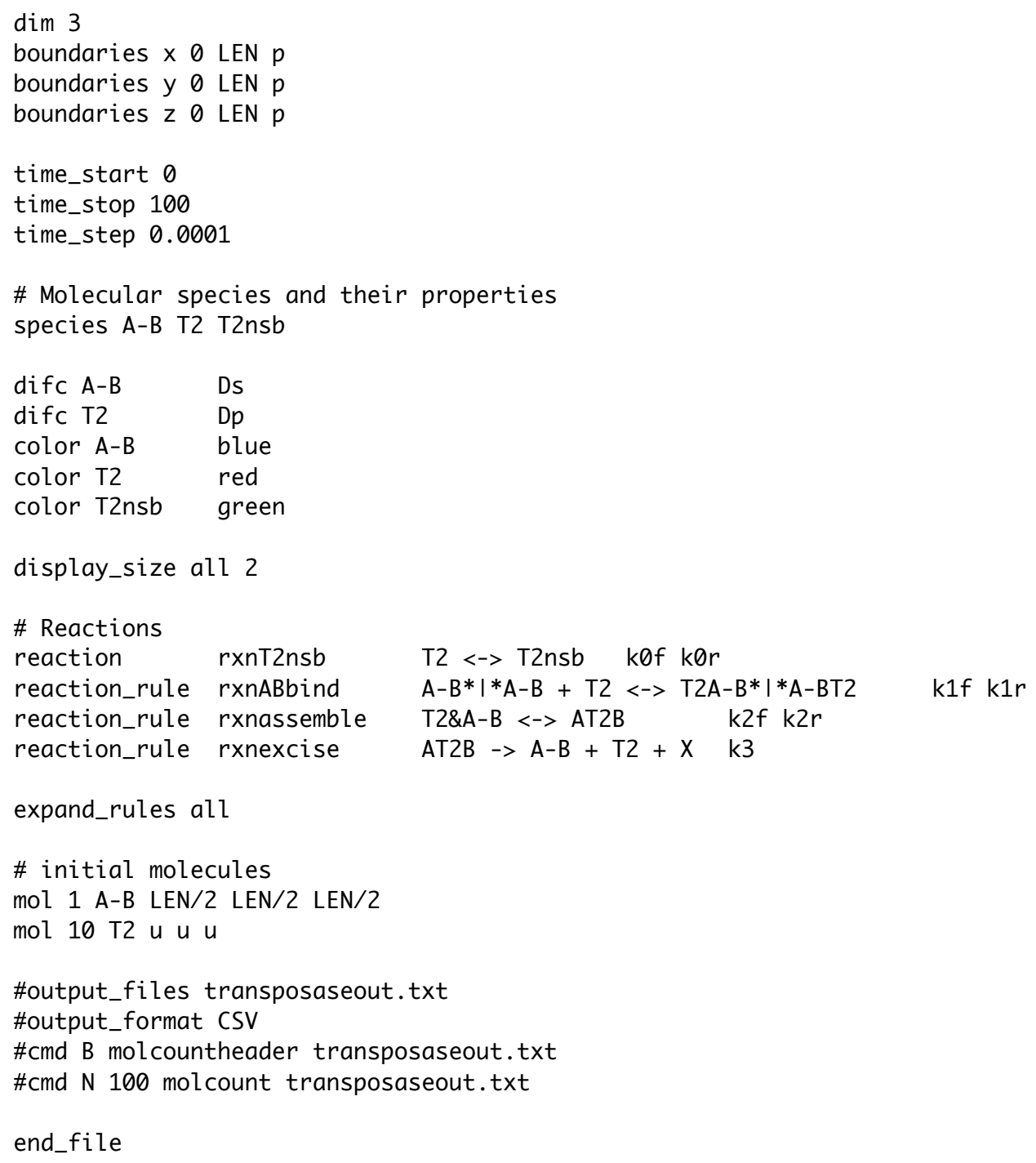




\section{Complexation of ABBA structure}

\section{$\underline{\text { Smoldyn input file }}$}

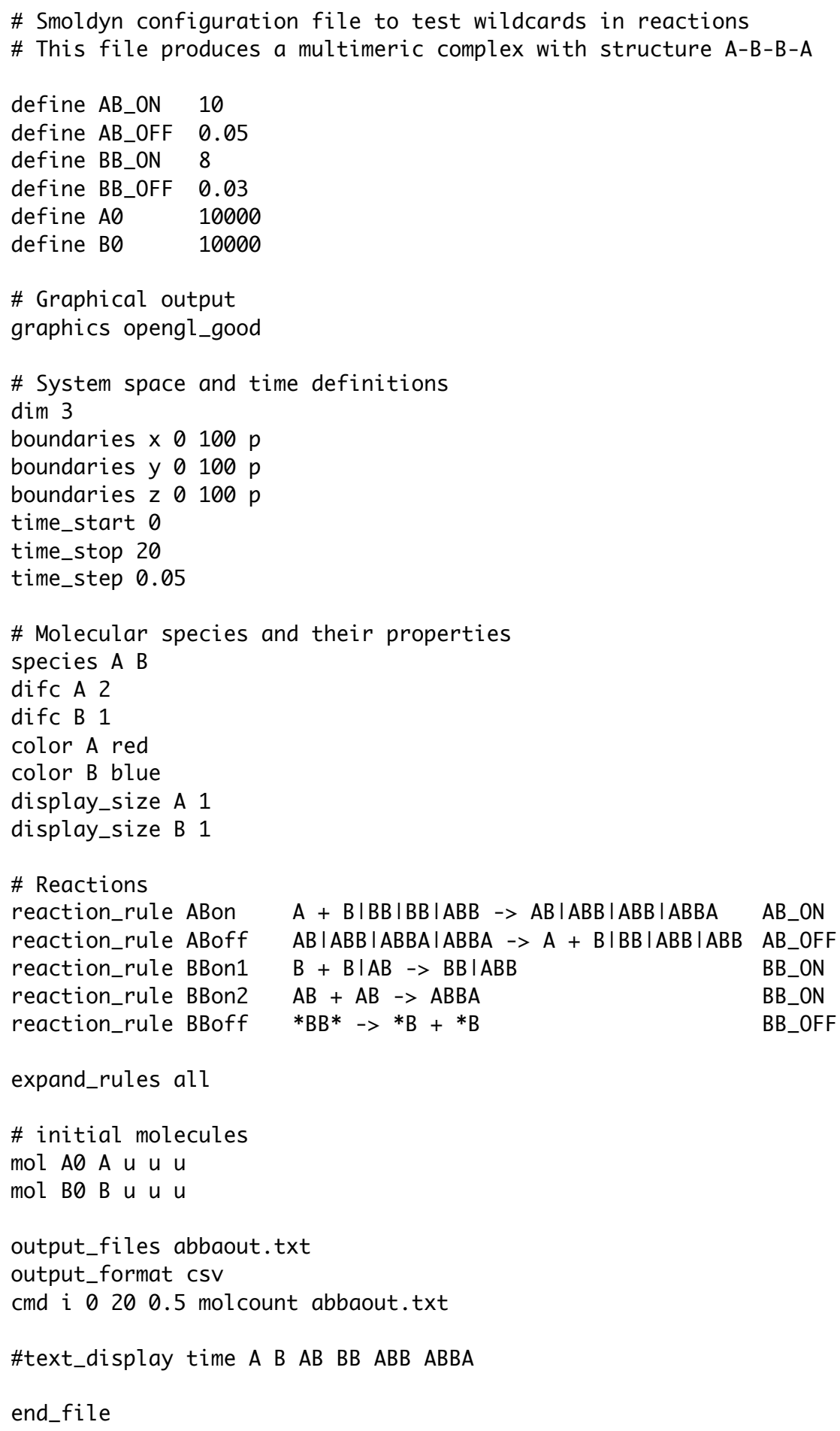




\section{MinD dimerization}

\section{Model parameters}

- Cell volume. The cytoplasmic volume of an E. coli cell is roughly $0.67 \mu^{3}$ (from BioNumbers ID 100011 (2) and (3)). However, this model assumes a slightly larger volume of $1 \mu \mathrm{m}^{3}$, which is $1 \mathrm{fl}$, in part because the MinD system is of particular interest in cells that are about to divide, which are larger than average cells.

- Number of MinD proteins. Shih et al. reported that there are about 2000 MinD protein copies per cell (4).

- ATP concentration and molecules. The ATP concentration varies widely between different individual cells but has an average value of about $1.54 \mathrm{mM}$ (from BioNumbers ID $111006(2)$ and (5)). In a volume of $1 \mathrm{fl}$, this is 930,000 molecules.

- ADP concentration and molecules. The ratio between ATP and ADP in exponentially growing cells ranges from 5.6 to 10.3, depending on growth conditions (BioNumbers ID 103384 (2) and (6)). This model assumes a ratio of 8, using the middle of this range. With this ratio and the assumption of 930,000 ATP molecules, there are about 116,000 ADP molecules in an E. coli cell. Alternatively, assuming an ATP concentration of 5.4 $\mathrm{nM}$ implies that the ADP concentration is $0.68 \mathrm{mM}$.

- MinD diffusion coefficient. MinD has a molecular weight of $29.6 \mathrm{kDa}$ (7). Combining this with a rule-of-thumb for computing diffusion coefficients in ref. (8) gives a diffusion coefficient of $2.6 \mu \mathrm{m}^{2} / \mathrm{s}$. The model uses this value. It is essentially identical to the 2.5 $\mu^{2} / \mathrm{s}$ value assumed in the Huang et al. model (9).

- Nucleotide exchange from $\mathrm{MinD}_{\mathrm{ADP}}$ to $\mathrm{MinD}_{\mathrm{ATP}}$. There are two possible mechanisms for conversion from $\mathrm{MinD}_{\mathrm{ADP}}$ to $\mathrm{MinD}_{\mathrm{ATP}}$ : transfer of just a phosphate group from free ATP to bound ADP, leading to free ADP and bound ATP, or exchange of entire nucleotides. Experiments with radiolabeled ATP showed that the latter mechanism is the correct one (10). There are no good in vivo values for the reaction rate constant for this reaction. Huang et al. (9) used a value of $1 \mathrm{~s}^{-1}$ for the reaction $\mathrm{MinD}_{\mathrm{ADP}} \rightarrow \mathrm{MinD}_{\mathrm{ATP}}$ without justification, except to note that it's within an observed range for guanine nucleotide exchange that spans 5 orders of magnitude; note that this is a pseudo-first order reaction because it ignores the ATP reactant. However, their model behavior agrees well with the experimental data, which does provide some justification for their parameters. Lacking better values, this model assumes a rate constant of $1 \mathrm{~s}^{-1}$. Dividing by the ATP concentration of $1.54 \mathrm{mM}$ gives a reaction rate constant of $650 \mathrm{M}^{-1} \mathrm{~s}^{-1}$ for the second order reaction $\mathrm{MinD}_{\mathrm{ADP}}+\mathrm{ATP} \rightarrow \mathrm{MinD}_{\mathrm{ATP}}+\mathrm{ADP}$. After unit conversion, this is $1.1 \times 10^{-6} \mu \mathrm{m}^{3} \mathrm{~s}^{-1}$. The model assumes this value for the nucleotide exchange from $\mathrm{MinD}_{\mathrm{ADP}}$ to $\mathrm{MinD}_{\mathrm{ATP}}$, represented here as $k_{D T}=1.1 \times 10^{-6} \mu^{3} \mathrm{~s}^{-1}$.

- Nucleotide exchange from $\mathrm{MinD}_{\mathrm{ATP}}$ to $\mathrm{MinD}_{\mathrm{ADP}}$. Lackner et al. showed that ATP competes about 3 times more effectively at binding to MinD than does ADP (their Figure 2B) (11). This contrasts crystal structure results, in (12), which suggests similar binding affinity. Based on the former result, this model assumes that the reaction rate constant 
for $\mathrm{MinD}_{\mathrm{ATP}}+\mathrm{ADP} \rightarrow \mathrm{MinD}_{\mathrm{ADP}}+\mathrm{ATP}$ is one third that of the reaction in the other direction, making it $k_{T D}=0.37 \times 10^{-6} \mu^{3} \mathrm{~s}^{-1}$.

- Nucleotide gain. There are no good data on the rate of nucleotide binding to unbound MinD in the reactions $\mathrm{MinD}_{\text {apo }}+\mathrm{ATP} \rightarrow \mathrm{MinD}_{\mathrm{ATP}}$ and $\mathrm{MinD}_{\text {apo }}+\mathrm{ADP} \rightarrow \mathrm{MinD}_{\mathrm{ADP}}$. Thus, this model assumes the same reaction rate constants as for the respective nucleotide

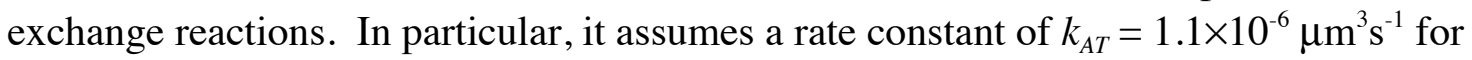
the former reaction and $k_{A D}=0.37 \times 10^{-6} \mu \mathrm{m}^{3} \mathrm{~s}^{-1}$ for the latter reaction.

- $\mathrm{MinD}_{\text {ATP }}$ nucleotide loss. To my knowledge, all published models of the Min system assume that all of the cell's MinD protein is bound to either ADP or ATP (e.g. refs. (9, 13, 14)). This model modifies this assumption slightly, assuming instead that the equilibrium concentration of $\mathrm{MinD}_{\text {ATP }}$ is 20-fold higher than that of $\mathrm{MinD}_{\text {apo }}$. The reaction $\mathrm{MinD}_{\text {apo }}+$ $\mathrm{ATP} \leftrightarrow \operatorname{MinD}_{\text {ATP }}$ is at equilibrium when $k_{A T}[\mathrm{ATP}]\left[\mathrm{MinD}_{\text {apo }}\right]=k_{T A}\left[\mathrm{MinD}_{\mathrm{ATP}}\right]$, using $k_{A T}$ and $k_{T A}$ as the forward and reverse reaction rate constants. From the prior numbers and the 20 -fold concentration difference assumption, $k_{T A}=0.05 \mathrm{~s}^{-1}$.

- $\mathrm{MinD}_{\mathrm{ADP}}$ nucleotide loss. At equilibrium, nucleotide exchange between $\mathrm{MinD}_{\mathrm{ATP}}$ and $\mathrm{MinD}_{\mathrm{ADP}}$ is in balance, so $\left[\mathrm{MinD}_{\mathrm{ATP}}\right] /\left[\mathrm{MinD}_{\mathrm{ADP}}\right]=k_{D T}[\mathrm{ATP}] /\left(k_{T D}[\mathrm{ADP}]\right)$. Also, ATP addition and removal is in balance, so $\left[\mathrm{MinD}_{\text {apo }}\right] /\left[\mathrm{MinD}_{\mathrm{ATP}}\right]=k_{T A} /\left(k_{A T}[\mathrm{ATP}]\right)$. Multiplying these equations gives $\left[\mathrm{MinD}_{\text {apo }}\right] /\left[\mathrm{MinD}_{\mathrm{ADP}}\right]=k_{D T} k_{T A} /\left(k_{T D} k_{A T}[\mathrm{ADP}]\right)$. Similarly, for the reaction $\mathrm{MinD}_{\text {apo }}+\mathrm{ADP} \leftrightarrow \mathrm{MinD}_{\mathrm{ADP}}$ is at equilibrium when $k_{A D}[\mathrm{ADP}]\left[\mathrm{MinD}_{\text {apo }}\right]=$ $k_{D A}\left[\mathrm{MinD}_{\mathrm{ADP}}\right]$, meaning that $\left[\mathrm{MinD}_{\text {apo }}\right] /\left[\mathrm{MinD}_{\mathrm{ADP}}\right]=k_{D A} /\left(k_{A D}[\mathrm{ADP}]\right)$. Setting these two results for the same ratio equal to each other and simplifying shows that $k_{D A}=$ $k_{D T} k_{T A} k_{A D} /\left(k_{T D} k_{A T}\right)$. Plugging in the numbers from above, $k_{A T}=0.05$, which is the same as the $k_{T A}$ value.

- $\mathrm{MinD}_{\mathrm{ATP}}$ dimerization and dissociation rate constants. $\mathrm{MinD}_{\mathrm{ATP}}$ has been shown to be predominantly dimeric when its concentration is above $2 \mu \mathrm{m}$, and primarily monomeric at lower concentrations (15). This model assumes this value for the $\mathrm{MinD}_{\text {ATP }}$ dissociation constant. There are no good data for the dimerization and dissociation rate constants, so this model assumes that the dissociation rate constant is $1 \mathrm{~s}^{-1}$ (making it the same as nucleotide exchange from $\mathrm{MinD}_{\mathrm{ADP}}$ to $\mathrm{MinD}_{\mathrm{ATP}}$ ). Combining this assumption with the dissociation constant implies that the association rate constant is $5 \times 10^{5} \mathrm{M}^{-1} \mathrm{~s}^{-1}$, which is $8.5 \times 10^{-4} \mu \mathrm{m}^{3} \mathrm{~s}^{-1}$.

- Other dimer dissociation rate constants. This model assumes the same dissociation rate constant for all MinD dimers. From above, this is $1 \mathrm{~s}^{-1}$.

- $\mathrm{MinD}_{\mathrm{ATP}}$ hydrolysis rate constant. The ATPase activity of MinD protein with excess ATP has been shown to be about 2.5 nmoles of ATP per mg of protein per minute (16). Converting units gives this rate constant as $1.2 \times 10^{-3} \mathrm{~s}^{-1}$.

\section{$\underline{\text { Smoldyn input file }}$}

\footnotetext{
\# Smoldyn configuration file for MinD dimerization and nucleotide dynamics

\# Units are microns and seconds
} 


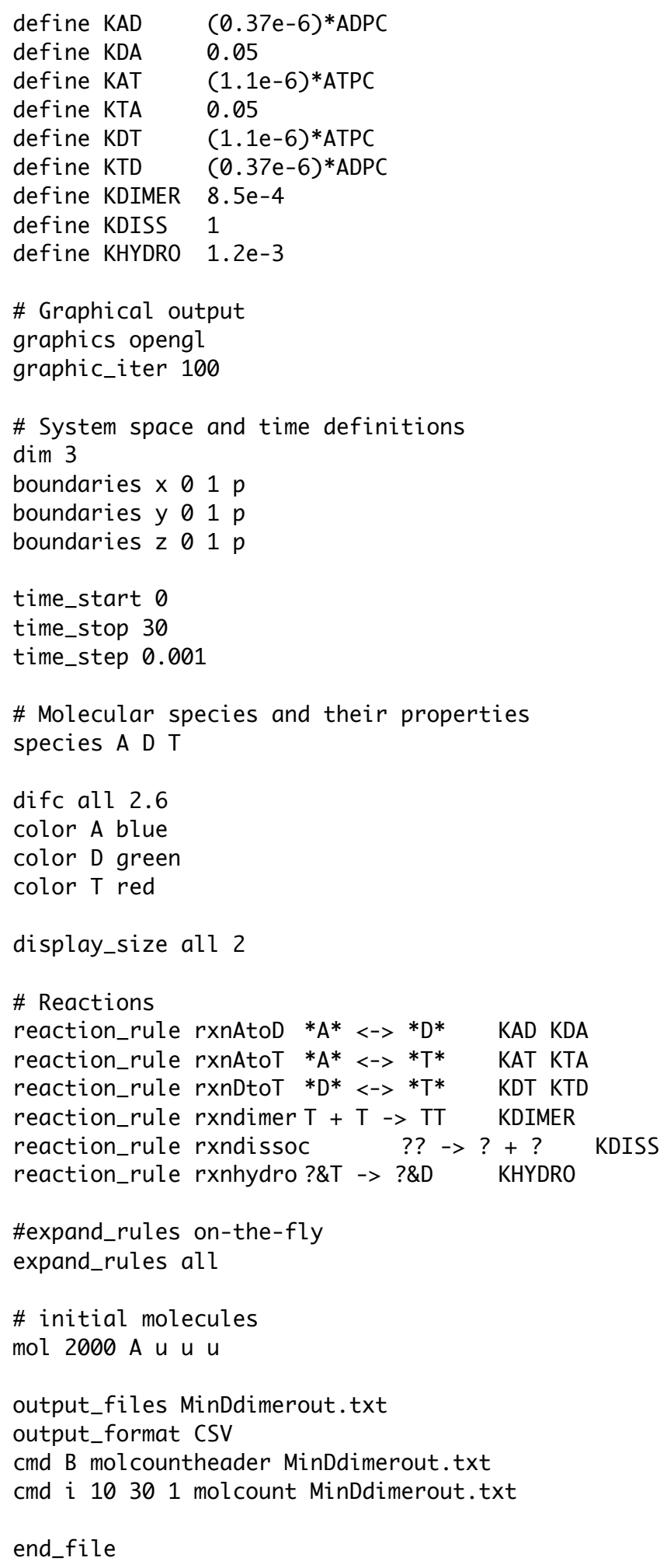




\section{Polymerization}

Theory for polymer length distribution

Consider the polymerization model "polymer_end1," in which polymerization and depolymerization arise through assembly and disassembly at one polymer end. It is expressed using the reaction rule: "A $+^{*}->A *$ ". This section shows that the equilibrium length distribution is exponential.

In this model, the association and dissociation rate constants, given here as $k_{f}$ and $k_{r}$, respectively, are the same for all polymer lengths. Based on this, define the association constant as

$$
K_{a}=\frac{k_{f}}{k_{r}}
$$

This is also the equilibrium constant for the dimerization reaction

$$
\mathrm{A}+\mathrm{A} \underset{k_{r}}{\stackrel{k_{f}}{\rightleftharpoons}} \mathrm{A}_{2}
$$

where the dimer is expressed here as $\mathrm{A}_{2}$, rather than as AA as it is in the simulation. As an equation, this means that

$$
K_{a}=\frac{\left[\mathrm{A}_{2}\right]}{[\mathrm{A}][\mathrm{A}]}
$$

where brackets denote concentrations. The same equilibrium constant applies to longer polymers too due to the assumption that the reaction rate constants are the same for all polymer lengths. Thus,

$$
K_{a}=\frac{\left[\mathrm{A}_{2}\right]}{[\mathrm{A}][\mathrm{A}]}=\frac{\left[\mathrm{A}_{3}\right]}{\left[\mathrm{A}_{2}\right][\mathrm{A}]}=\cdots=\frac{\left[\mathrm{A}_{n}\right]}{\left[\mathrm{A}_{n-1}\right][\mathrm{A}]}
$$

Rearrangement leads to

$$
\begin{gathered}
{\left[\mathrm{A}_{2}\right]=K_{a}[\mathrm{~A}]^{2}} \\
{\left[\mathrm{~A}_{3}\right]=K_{a}^{2}[\mathrm{~A}]^{3}} \\
\cdots \\
{\left[\mathrm{A}_{n}\right]=K_{a}^{n-1}[\mathrm{~A}]^{n}}
\end{gathered}
$$

In addition to the prior assumptions, suppose the total concentration of polymer units is fixed at $\left[\mathrm{A}_{\text {tot. }}\right]$. This is equal to

$$
\left[\mathrm{A}_{\text {tot. }}\right]=[\mathrm{A}]+2\left[\mathrm{~A}_{2}\right]+\cdots+n\left[\mathrm{~A}_{n}\right]+\cdots
$$

Substituting in the prior result and simplifying leads to

$$
\left[\mathrm{A}_{\text {tot. }}\right]=\frac{1}{K_{a}} \sum_{n=1}^{\infty} n K_{a}^{n}[\mathrm{~A}]^{n}=\frac{[\mathrm{A}]}{\left(K_{a}[\mathrm{~A}]-1\right)^{2}}
$$


where the latter equality follows from a standard summation identity. Expanding and rearranging the latter equality leads to a quadratic equation in [A],

$$
0=K_{a}^{2}\left[\mathrm{~A}_{t o t}\right][\mathrm{A}]^{2}-\left(1+2 K_{a}\left[\mathrm{~A}_{t o t .}\right]\right)[\mathrm{A}]+\left[\mathrm{A}_{t o t}\right]
$$

The solutions are

$$
\frac{[\mathrm{A}]}{\left[\mathrm{A}_{t o t .}\right]}=\frac{1+2 K_{a}\left[\mathrm{~A}_{t o t}\right] \pm \sqrt{1+4 K_{a}\left[\mathrm{~A}_{t o t .}\right]}}{2 K_{a}^{2}\left[\mathrm{~A}_{t o t}\right]^{2}}
$$

To determine whether the positive or negative root is the correct one, consider the case with low association, where $K_{a}[\mathrm{~A}] \ll 1$. From above, this implies that $\left[\mathrm{A}_{n}\right] /[\mathrm{A}] \ll<$ for all $n>1$ and also that $[\mathrm{A}] \approx\left[\mathrm{A}_{\text {tot. }}\right]$. In this case, the square root in the quadratic equation can be expanded using a Taylor series, leading to

$$
\frac{[\mathrm{A}]}{\left[\mathrm{A}_{t o t .}\right]}=\frac{1+2 K_{a}\left[\mathrm{~A}_{t o t .}\right] \pm\left(1+2 K_{a}\left[\mathrm{~A}_{t o t .}\right]-2 K_{a}^{2}\left[\mathrm{~A}_{t o t .}\right]^{2}+O\left(K_{a}^{3}\left[\mathrm{~A}_{t o t .}\right]^{3}\right)\right)}{2 K_{a}^{2}\left[\mathrm{~A}_{t o t .}\right]^{2}}
$$

The solution with the positive sign simplifies to

$$
\frac{[\mathrm{A}]}{\left[\mathrm{A}_{t o t .}\right]} \approx \frac{1}{K_{a}^{2}\left[\mathrm{~A}_{t o t .}\right]^{2}}
$$

The value of the right hand side is much greater than 1 for this low association case, which disagrees with the statement made earlier that $[\mathrm{A}] \approx\left[\mathrm{A}_{\text {tot. }}\right]$, implying that this is the incorrect solution. The solution with the negative sign simplifies to

$$
\frac{[\mathrm{A}]}{\left[\mathrm{A}_{t o t .}\right]}=1-O\left(K_{a}\left[\mathrm{~A}_{t o t .}\right]\right)
$$

This agrees with prior statements, implying that the negative sign leads to the correct solution.

Thus, the equilibrium distribution of polymer lengths can be calculated from the two following equations, both of which are copied from above,

$$
\begin{aligned}
& {[\mathrm{A}]=\left[\mathrm{A}_{t o t .}\right] \frac{1+2 K_{a}\left[\mathrm{~A}_{t o t .}\right]-\sqrt{1+4 K_{a}\left[\mathrm{~A}_{t o t .}\right]}}{2 K_{a}^{2}\left[\mathrm{~A}_{t o t .}\right]^{2}}} \\
& {\left[\mathrm{~A}_{n}\right]=K_{a}^{n-1}[\mathrm{~A}]^{n}}
\end{aligned}
$$

This shows that the length distribution depends exponentially on the polymer length, in agreement with prior results by Flory (17).

Next consider the model "polymer_end2", which is identical to the one just shown except that monomer dimerization, through the reaction $\mathrm{A}+\mathrm{A} \rightarrow \mathrm{A}_{2}$, has twice the association reaction rate. Using the same definition for $K_{a}$ as before, 


$$
\frac{\left[\mathrm{A}_{2}\right]}{[\mathrm{A}][\mathrm{A}]}=2 K_{a} \quad \frac{\left[\mathrm{A}_{3}\right]}{\left[\mathrm{A}_{2}\right][\mathrm{A}]}=\cdots=\frac{\left[\mathrm{A}_{n}\right]}{\left[\mathrm{A}_{n-1}\right][\mathrm{A}]}=K_{a}
$$

In the latter equation, $n$ can adopt values of 2 or larger. Following the same procedure as before, these rearrange to

$$
\begin{aligned}
{\left[\mathrm{A}_{2}\right] } & =2 K_{a}[\mathrm{~A}]^{2} \\
{\left[\mathrm{~A}_{3}\right] } & =2 K_{a}^{2}[\mathrm{~A}]^{3} \\
& \ldots \\
{\left[\mathrm{A}_{n}\right] } & =2 K_{a}^{n-1}[\mathrm{~A}]^{n}
\end{aligned}
$$

Substituting into the $\left[\mathrm{A}_{\text {tot. }}\right]$ definition leads to

$$
\left[\mathrm{A}_{\text {tot. }}\right]=\frac{2}{K_{a}} \sum_{n=1}^{\infty} n K_{a}^{n}[\mathrm{~A}]^{n}-[\mathrm{A}]=\frac{2[\mathrm{~A}]}{\left(K_{a}[\mathrm{~A}]-1\right)^{2}}-[\mathrm{A}]
$$

Expanding and rearranging the latter equality leads to a cubic equation in $[\mathrm{A}]$, which is too complex to solve here. However, importantly, the length distribution is still exponential for $n \geq 2$,

$$
\left[\mathrm{A}_{n}\right]=2 K_{a}^{n-1}[\mathrm{~A}]^{n}
$$

Also, the actual monomer concentration, [A], is half of the value that would be predicted from this equation.

The "polymer_mid" model is more difficult to evaluate because it has many more reactions. Of these reactions, all of the forward reaction rate constants are the same; they are all twice as large as the values in the "polymer_end1" model due to the fact that association can happen with either reactant ending up on the "left" side of the product. Also, all of the reverse reaction constants for asymmetric dissociation are the same; they are also twice as large as the values in the "polymer_end1" model, in this case because there are two ways for each asymmetric dissociation to arise. However, the reverse reaction constants for symmetric dissociation are a factor of two smaller than the others because each of these dissociations can only happen in one way. There are many fewer of these latter reactions than the others, so nearly all of the reaction equilibrium constants are the same as for the "polymer_end1" model, which also leads to the same equilibrium polymer length distribution. Figure 3 of the main text shows this result. Nevertheless, the slower dissociations for symmetric species undoubtedly affect the length distribution, and this should be particularly noticeable for small polymers because symmetric dissociations are a larger fraction of their total dissociations. Indeed, the simulation data shown in the figure shows a small but statistically significant deviation away from the exponential line for small polymer sizes, presumably arising from this effect.

The standard deviation for the equilibrium populations of different polymer lengths can be computed from the standard result that, when at equilibrium, the probability density for the population size for any individual chemical species obeys a Poisson 
distribution. A Poisson distribution has the variance equal to its mean, so the standard deviation is the square root of the mean.

\section{Polymer length distribution figure}

The following figure shows equilibrium polymer length distributions for all three models tested here. As in Figure 3 of the main text, red dots represent the "polymer_end1" model, blue dots represent the "polymer_mid" model, the solid black line represents the theoretical exponential distribution, and the dashed black lines represent the theoretical computation for one standard deviation away from the exponential distribution. In addition, the green dots represent the "polymer_end2" model. These points agree qualitatively with the predictions described above.

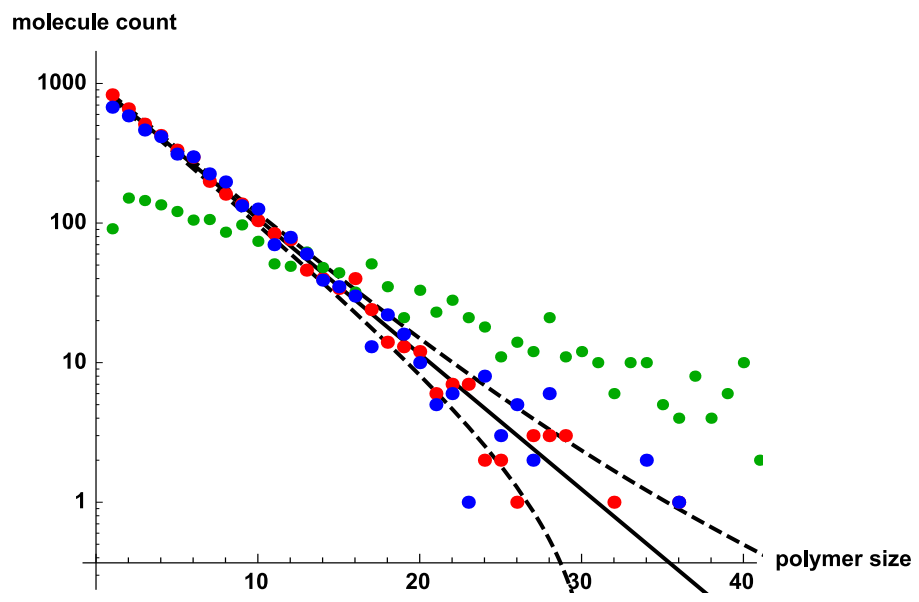

Smoldyn input file for polymer_end1 model

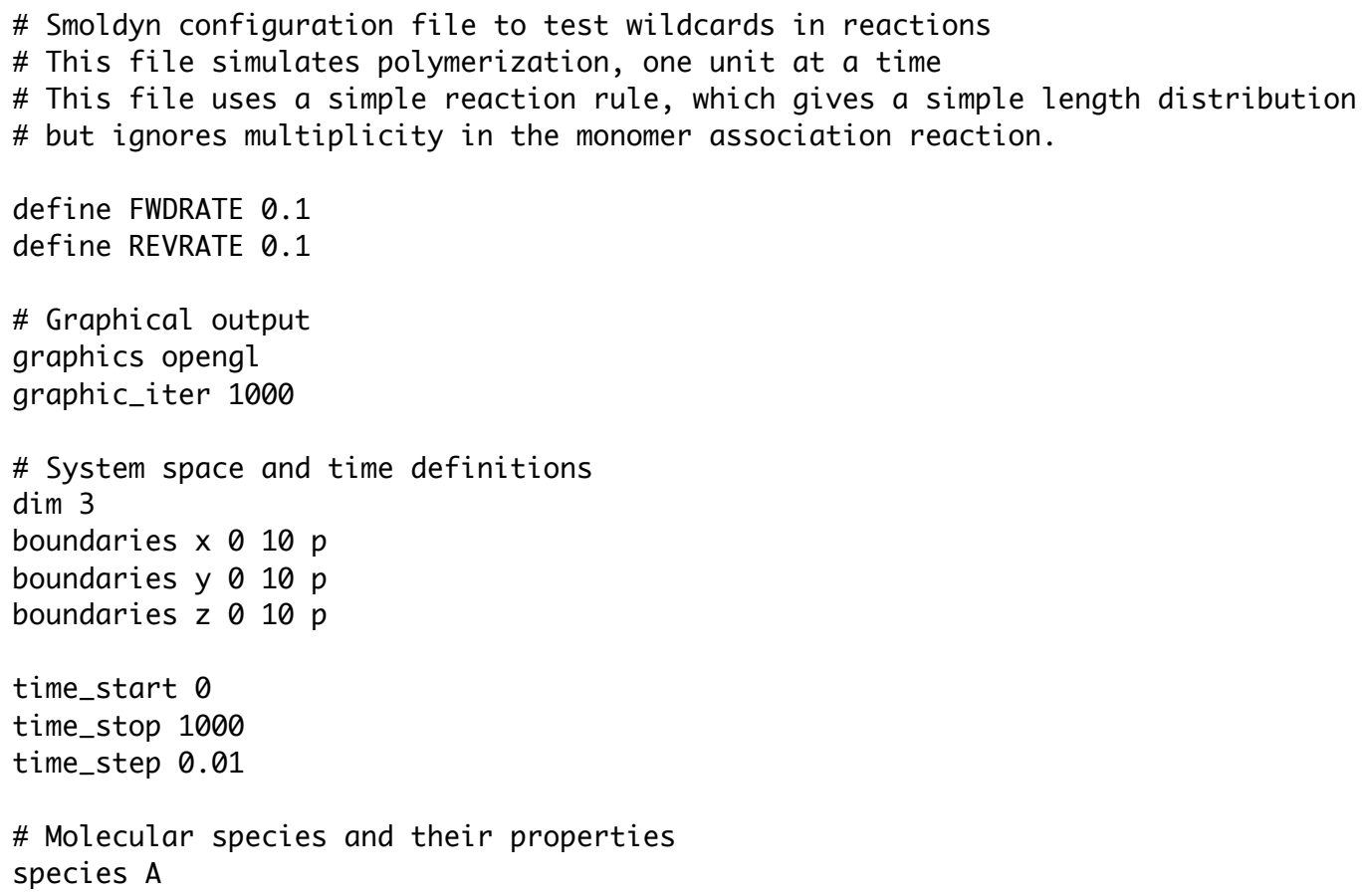


difc A 1

color A red

display_size A(all) 2

\# Reactions

reaction_rule $r \times n *+A<->*^{*} \quad$ FWDRATE REVRATE

expand_rules on-the-fly

\# This reaction rule has the same reaction rate for all reactions. This may be \# correct, depending on the model. However, it is probably more accurate for the \# the monomer association reaction to be twice as fast, because its association can \# happen in either of two ways. This change, in polymer_end2.txt, makes the model \# consistent with tbe BioNetGen model of essentially the same name.

\# initial molecules

mol 20000 A u u u

cmd A diagnostics all

output_files polymer_end1out.txt stdout

output_format csv

cmd N 1000 molcount polymer_end1out.txt

cmd N 1000 molcount stdout

end_file

\section{$\underline{\text { Smoldyn input file for polymer_end2 model }}$}

\# Smoldyn configuration file to test wildcards in reactions

\# This file simulates polymerization, one unit at a time

\# This file uses more complex reaction rules, which is slightly less simple to analyze

\# but correctly accounts for multiplicity in the monomer reaction rate.

define FWDRATE 0.1

define REVRATE 0.1

\# Graphical output

graphics opengl

graphic_iter 1000

\# System space and time definitions

$\operatorname{dim} 3$

boundaries $\times 010 \mathrm{p}$

boundaries y $010 \mathrm{p}$

boundaries y $010 \mathrm{p}$

time_start 0

time_stop 4000

\# polymers are longer here than in polymer_end1, so equilibration takes longer

time_step 0.01

\# Molecular species and their properties

species A

difc A 1

color A red

display_size A 2

\# Reactions 


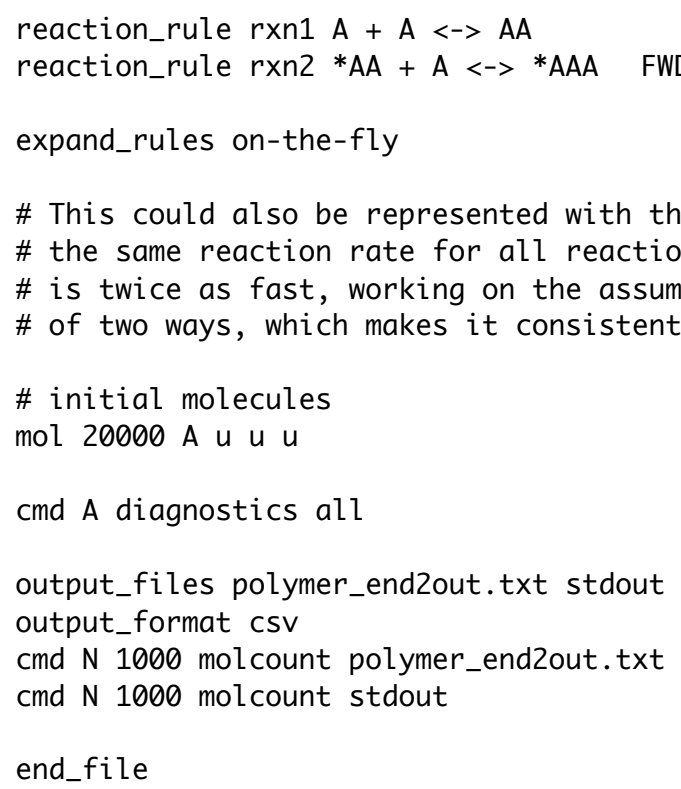

\section{$\underline{\text { Smoldyn input file for polymer_mid model }}$}

\# Smoldyn configuration file to test wildcards in reactions

\# This file simulates polymerization, where any two polymers can join end-to-end, \# or any polymer can divide at any place.

define FWDRATE 0.1

define REVRATE 0.1

\# Graphical output

graphics opengl

graphic_iter 1000

\# System space and time definitions

$\operatorname{dim} 3$

boundaries $\times 010 \mathrm{p}$

boundaries y $010 \mathrm{p}$

boundaries z $010 \mathrm{p}$

time_start 0

time_stop 1000

time_step 0.01

\# Molecular species and their properties

species $A$

difc A 1

color A red

display_size A(all) 2

\section{\# Reactions}

reaction_rule $r \times n *+*<* * \quad 2 *$ FWDRATE REVRATE

\# the forward reaction rate is multiplied by 2 because the wildcards only consider a \# single possible bond with a reaction, whereas the reaction allows two possible bonds, \# which are on the left and right sides of the first reactant.

expand_rules on-the-fly 
bioRxiv preprint doi: https://doi.org/10.1101/112052; this version posted February 27, 2017. The copyright holder for this preprint (which was not certified by peer review) is the author/funder, who has granted bioRxiv a license to display the preprint in perpetuity. It is made available under aCC-BY 4.0 International license.

\author{
\# initial molecules \\ mol 20000 A u u u \\ output_files polymer_midout.txt stdout \\ output_format csv \\ cmd N 1000 molcount polymer_midout.txt \\ cmd N 1000 molcount stdout \\ cmd A diagnostics all \\ end_file
}




\section{Transcription and translation}

The model here uses numbers that are approximately correct for a Saccharomyces cerevisiae yeast cell. In particular, it uses a spherical cell geometry with a plasma membrane radius of $2.5 \mu \mathrm{m}$ and a nuclear radius of $1 \mu \mathrm{m}$; typical cell values are 2.5 to 5 $\mu \mathrm{m}$ and $0.9 \mu \mathrm{m}(\mathbf{1 8})$, respectively. The simulation runs for $10,000 \mathrm{~s}$, which is about 2.8 hours; typical cell generation times are around 1.5 to 2.3 hours in rich media (19).

The simulation assumed that diffusion coefficients were: $4 \mu \mathrm{m}^{2} / \mathrm{s}$ for ribosomes, 0.1 $\mu \mathrm{m}^{2} / \mathrm{s}$ for DNA, $8 \mu \mathrm{m}^{2} / \mathrm{s}$ for RNA, and $22 \mu \mathrm{m}^{2} / \mathrm{s}$ for proteins. The ribosome value of 4 $\mu \mathrm{m}^{2} / \mathrm{s}$ is from equations and advice in Note 3 of ref. (8) along with the $3200 \mathrm{kDa}$ molecular weight of a ribosome. The DNA value of $0.1 \mu \mathrm{m}^{2} / \mathrm{s}$ is a very rough approximation. If the DNA sequence in the model were the complete DNA strand, then it would have a much faster diffusion coefficient (20) but if it is assumed that the DNA is actually a small portion of a much larger chromosome, then it would not diffuse freely. Instead, it would diffuse over a small region with so-called segmental diffusion (21), with a very small diffusion coefficient, likely on the order of $10^{-4} \mu \mathrm{m}^{2} / \mathrm{s}$ (see (1)). Similarly, the RNA diffusion coefficient would be several-fold faster than the $8 \mu \mathrm{m}^{2} / \mathrm{s}$ in the simulation if the simulated RNA sequences were the entire molecule and it diffused as a sphere (based on $\sim 500 \mathrm{Da} /$ basepair and equations in Note 3 of ref. (8)). However, yeast mRNAs typically include untranslated regions and poly(A) tails which substantially increase their molecular weights. Finally, the protein diffusion coefficient of $22 \mu \mathrm{m}^{2} / \mathrm{s}$ is taken from the value for GFP diffusion in eukaryotic cytoplasms $(22,23)$.

\section{Smoldyn model}

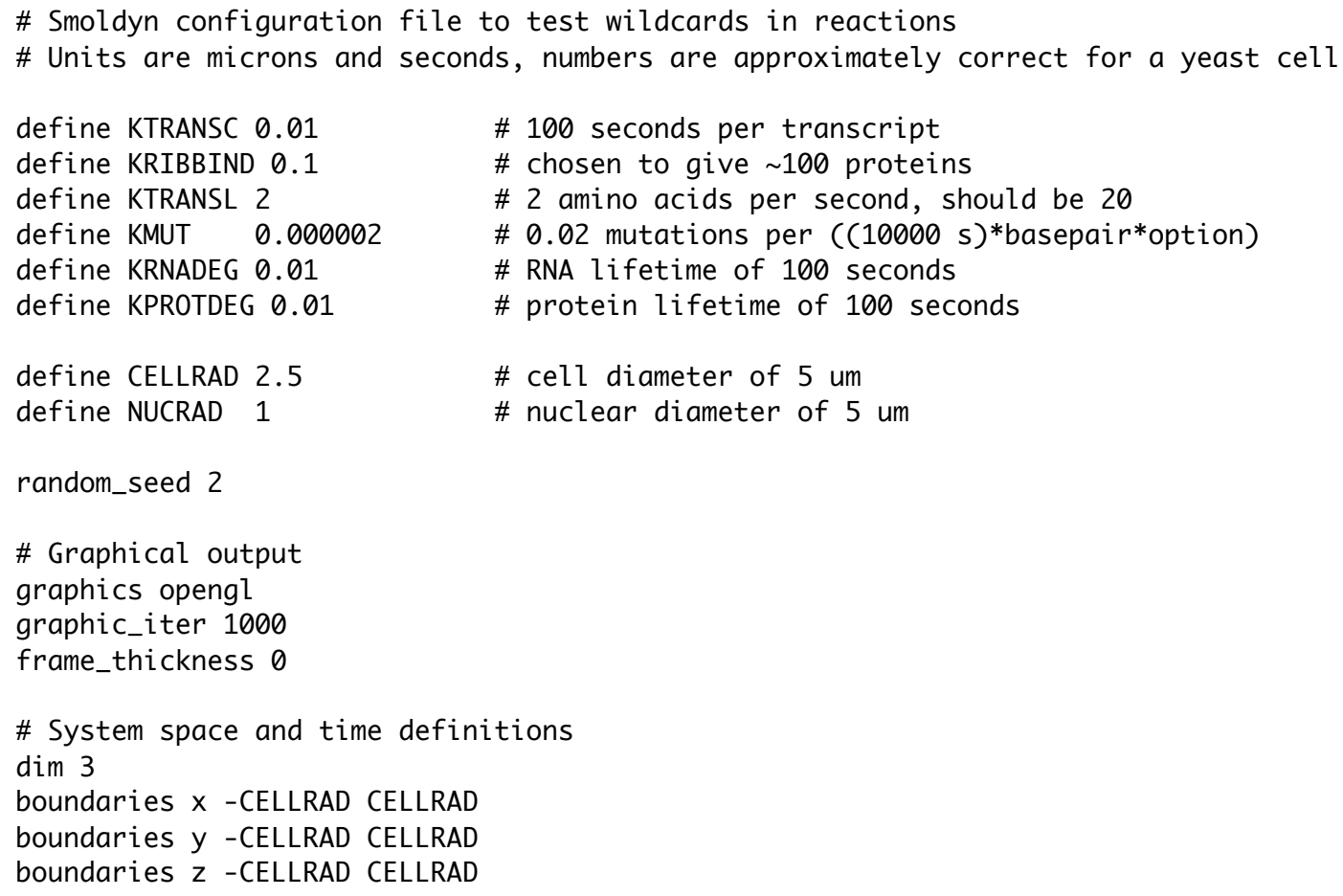




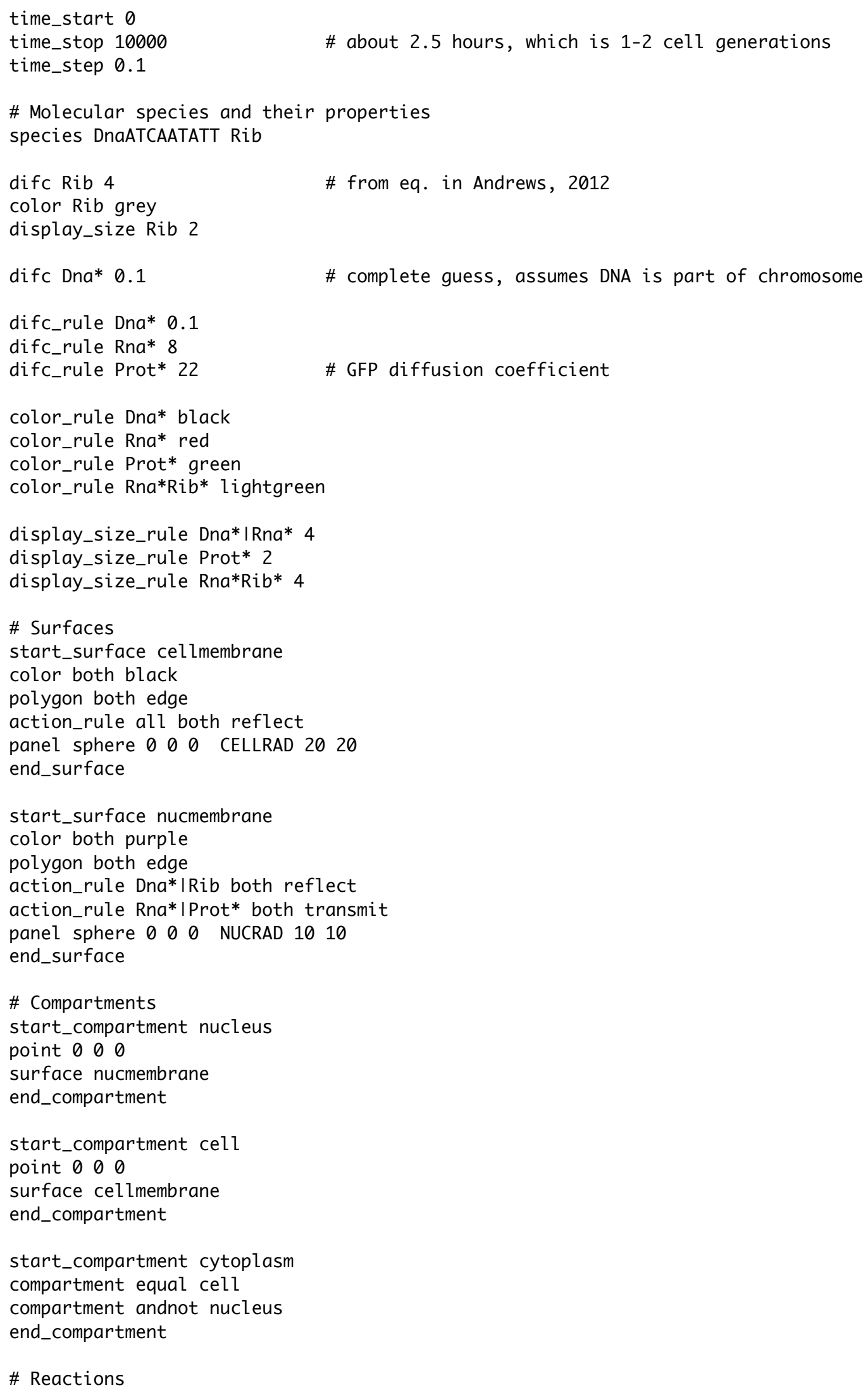




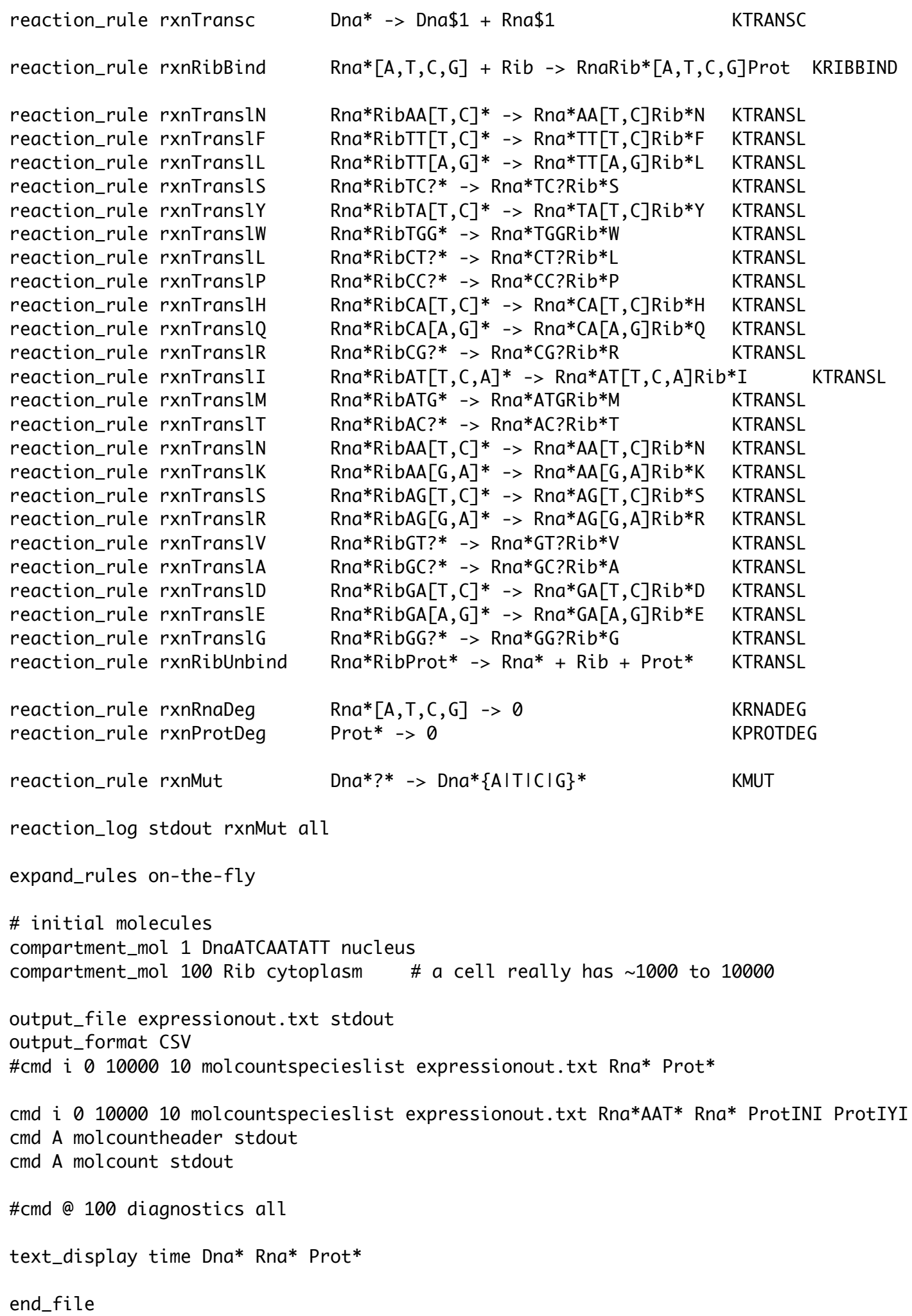




\section{References}

1. Claeys Bouuaert, C., Lipkow, K., Andrews, S. S., Liu, D., and Chalmers, R. (2013) The autoregulation of a eukaryotic DNA transposon eLife 2, e00668.

2. Milo, R., Jorgensen, P., Moran, U., Weber, G., and Springer, M. (2010) BioNumbers - the database of key numbers in molecular and cell biology Nucleic Acids Res. 38, D750-D53.

3. Neidhardt, F. C., and Umbarger, H. E. (1996) Chemical composition of Escherichia coli in Escherichia coli and Salmonella (Neidhardt, F. C., Ed.), ASM Press, Washington DC.

4. Shih, Y.-L., Fu, X., King, G. F., Le, T., and Rothfield, L. (2002) Division site placement in E. coli: mutations that prevent formation of the MinE ring lead to loss of the normal midcell arrest of growth of polar MinD membrane domains EMBO J.21, 3347-57.

5. Yaginuma, H., Kawai, S., Tabata, K. V., Tomiyama, K., Kakizuka, A., Komatsuzaki, T., Noji, H., and Imamura, H. (2014) Diversity in ATP concentrations in a single bacterial cell population revealed by quantitative single-cell imaging Scientific Reports 4, 6522.

6. Tran, Q. H., and Unden, G. (1998) Changes in the proton potential and the cellular energetics of Escherichia coli during growth by aerobic and anaerobic respiration or by fermentation Eur. J. Biochem. 251, 538-43.

7. de Boer, P. A. J., Crossley, R. E., and Rothfield, L. I. (1989) A division inhibitor and a topological specificity factor coded for by the minicell locus determine proper placement of the division septum in E. coli Cell 56, 641-49.

8. Andrews, S. S. (2012) Spatial and stochastic cellular modeling with the Smoldyn simulator Methods in Molecular Biology 804, 519-42.

9. Huang, K. C., Meir, Y., and Wingreen, N. S. (2003) Dynamic structures in Escherichia coli: spontaneous formation of MinE rings and MinD polar zones Proc. Natl. Acad. Sci. USA 100, 12724-28.

10. de Boer, P. A. J., Crossley, R. E., Hand, A. R., and Rothfield, L. I. (1991) The MinD protein is a membrane ATPase required for the correct placement of the Escherichia coli division site EMBO J.10,4371-80.

11. Lackner, L. L., Raskin, D. M., and de Boer, P. A. J. (2003) ATP-dependent interactions between Escherichia coli Min proteins and the phospholipid membrane in vitro $J$. Bact. 185, 735-49.

12. Hayashi, I., Oyama, T., and Morikawa, K. (2001) Structural and functional studies of MinD ATPase: implications for the molecular recognition of the bacterial cell division apparatus EMBO J. 20, 1819-28. 
13. Kerr, R. A., Levine, H., Sejnowski, T. J., and Rappel, W.-J. (2006) Division accuracy in a stochastic model of Min oscillations in Escherichia coli Proc. Natl. Acad. Sci. USA 103, 347-52.

14. Arjunan, S. N. V., and Tomita, M. (2010) A new multicompartmental reactiondiffusion modeling method links transient membrane attachment of E. coli MinE to E-ring formation Systems and Synthetic Biology 4, 35-53.

15. Hu, Z., and Lutkenhaus, J. (2003) A conserved sequence at the C-terminus of MinD is required for binding to the membrane and targeting MinC to the septum Mol. Microbiol. 47, 345-55.

16. Hu, Z., and Lutkenhaus, J. (2001) Topological regulation of cell division in E. coli. Spatiotemporal oscillation of MinD requires stimulation of its ATPase by MinE and phospholipid Mol.Cell 7, 1337-43.

17. Flory, P. J. (1953) Principles of Polymer Chemistry, Cornell University Press, Ithaca, NY.

18.Jorgensen, P., Edgington, N. P., Schneider, B. L., Rupes, I., Tyers, M., and Futcher, B. (2007) The size of the nucleus increases as yeast cells grow Mol. Biol. of the Cell 18, 3523-32.

19. Sherman, F. (2002) Getting started with yeast Methods in Enzymology 350, 3-41.

20. Verkman, A. S. (2002) Solute and macromolecule diffusion in cellular aqueous compartments Trends Biochem. Sci. 27, 27-33.

21. Berg, O. G. (1984) Diffusion-controlled protein-DNA association: influence of segmental diffusion of the DNA Biopolymers 23, 1869-89.

22. Swaminathan, R., Hoang, C. P., and Verkman, A. S. (1997) Photobleaching recovery and anisotropic decay of green fluorescent protein GFP-S65T in solution and cells: cytoplasmic viscosity probed by green fluorescent protein translational and rotational diffusion Biophys. J. 72, 1900-07.

23. Dix, J. A., and Verkman, A. S. (2008) Crowding effects on diffusion in solutions and cells Ann. Rev. Biophys. 37, 247-63. 